\title{
A parametric analysis of prospect theory's functionals for the general population
}

\author{
Adam S. Booij • Bernard M. S. van Praag • \\ Gijs van de Kuilen
}

Published online: 28 April 2009

(C) The Author(s) 2009. This article is published with open access at Springerlink.com

\begin{abstract}
This article presents the results of an experiment that completely measures the utility function and probability weighting function for different positive and negative monetary outcomes, using a representative sample of $N=1,935$ from the general public. The results confirm earlier findings in the lab, suggesting that utility is less pronounced than what is found in classical measurements where expected utility is assumed. Utility for losses is found to be convex, consistent with diminishing sensitivity, and the obtained loss-aversion coefficient of 1.6 is moderate but in agreement with contemporary evidence. The estimated probability weighting functions have an inverse-S shape and they imply pessimism in both domains. These results show that probability weighting is also an important phenomenon in the general population. Women and lower educated individuals are found to be more risk averse, in agreement with common findings. In contrast to previous studies that ascribed gender differences in risk attitudes solely to differences in the degree utility curvature, however, our results show that this finding is primarily driven by loss aversion and, for women, also by a more pessimistic psychological response toward the probability of obtaining the best possible outcome.
\end{abstract}

Keywords Prospect theory · Utility for gains and losses · Loss aversion · Subjective probability weighting

\footnotetext{
A. S. Booij $(\varangle)$

Amsterdam School of Economics, Roetersstraat 11, 1018 WB Amsterdam, The Netherlands e-mail: Adam.Booij@uva.nl

B. M. S. van Praag

Amsterdam School of Economics, Tinbergen Institute, Cesifo, IZA, DIW, Roetersstraat 11, 1018 WB Amsterdam, The Netherlands

G. van de Kuilen

TIBER, CentER, Tilburg University, P.O. Box 90153, 5000 LE Tilburg, The Netherlands
} 


\section{Introduction}

After numerous studies systematically falsified the classical expected utility model as descriptive theory of decision making under risk (Allais 1953; Kahneman and Tversky 1979), various new descriptive theories of individual decision making under risk have been developed (Starmer 2000). The most prominent of these non-expected utility models is the prospect theory (Kahneman and Tversky 1979; Tversky and Kahneman 1992).

Prospect theory entails two fundamental breakaways from the classical model. Instead of defining preferences over wealth, preferences are defined over changes with respect to a flexible reference point, often taken as the status quo. Decision makers are assumed to be less sensitive to changes in outcomes further away from this reference point, which is called diminishing sensitivity, and it is assumed that negative changes (losses) hurt more than positive changes (gains), a phenomenon called loss aversion. This generalization helps to explain phenomena such as the equity premium puzzle (Benartzy and Thaler 1995), downward-sloping labor supply (Goette et al. 2004), the End-of-the-day-Effect in horse race betting (McGlothlin 1956), and the co-existence of appreciable small stake- and moderate large stake-risk aversion (Rabin 2000). Furthermore, linearity in probability is replaced by a subjective probability weighting function that is assumed to have an inverse-S shape, reflecting increased sensitivity toward changes in probabilities near 0 and 1 . This accommodates anomalies of the classical model such as the Allais paradox (1953), the co-existence of gambling and insurance, betting on long-shots at horse races (Jullien and Salanié 2000), and the avoidance of probabilistic insurance (Wakker et al. 1997). ${ }^{1}$

The generalization that prospect theory entails breaks the one-to-one relationship between utility curvature and risk attitudes that holds under expected utility. Hence, in the prospect theory framework, risk attitudes are jointly determined by utility curvature and subjective probability weighting, where outcomes are defined as changes with respect to the status quo. This adds complexity to the interpretation of the degree of risk aversion (preferring the expected value of a prospect to the prospect itself), as it can no longer be summarized into a single index of curvature (Wakker 1994), and it complicates the empirical determination of risk aversion, because of the simultaneous confounding effects of utility curvature and subjective probability weighting (Tversky and Kahneman 1992).

In order to test prospect theory's hypotheses about the specific functional forms and to quantify the sources of risk aversion, various authors have attempted to empirically determine the prevailing shape for the utility- and probability-weighting functions. These studies deal with the simultaneity problem by either assuming a parametric form for these functions (Tversky and Kahneman 1992; Camerer and Ho 1994; Tversky and Fox 1995; Donkers et al. 2001; Harrison and Rutström 2009; Abdellaoui et al. 2008) or by exploiting a particular design that permits them to be disentangled non-parametrically (Wakker and Deneffe 1996; Abdellaoui 2000; Bleichrodt and Pinto 2000; Abdellaoui et al. 2007b).

\footnotetext{
1 For a survey of examples of field phenomena that prospect theory can and expected utility cannot explain, see Camerer (2000).
} 
Both approaches have their advantages and drawbacks. The parametric approaches are easy to estimate and interpret, but they suffer from a contamination effect: a misspecification of the utility function will also bias the estimated probability weighting function and vice versa (Abdellaoui 2000). For instance, in the parametric estimation of prospect theory, Harrison and Rutström (2009) assume the one parameter probability weighting function introduced by Tversky and Kahneman (1992). This function may be a misspecification if the true weighting function exhibits underweighting for intermediate and large probabilities, and minimal overweighting of small probabilities. Moreover, the authors assume the probability weighting function for gains and losses to be equal. This assumption will directly affect the loss aversion measure if the degree of pessimism differs between both domains. Donkers et al. (2001) impose the same restriction and use a one parameter weighting function proposed by Prelec (1998). Both studies find relatively much utility curvature and a low degree of loss aversion compared to the non-parametric approaches, which suggests that the probability weighting function may have been misspecified. Another disadvantage of the parametric approach is that allowing for unobserved heterogeneity in the model is necessarily parametric which means the results may depend on the choice of the stochastic error process (Wilcox 2008, p. 265).

The non-parametric methods do not have these problems as no functional forms are assumed beforehand and estimation is conducted at the individual level allowing for full heterogeneity. This approach, however, requires data that have a chained nature which may introduce error propagation leading to less precise inference (Wakker and Deneffe 1996; Blavatskyy 2006) and, in theory, an incentive compatibility problem (Harrison and Rutström 2008).

This article aims at combining the best of both approaches by parametrically estimating the complete prospect theory model, thereby allowing for decision errors, using a rich dataset that permits the identification of prospect theory's functionals without making stringent parametric assumptions. The results have relevance for the empirical issue of whether the utility for losses is convex (Currim and Sarin 1989; Tversky and Kahneman 1992; Abdellaoui 2000; Etchart-Vincent 2004) or concave (Davidson et al. 1957; Laury and Holt 2000 (for real incentives only); Fehr-Duda et al. 2006; Abdellaoui et al. 2008) and also whether the prevailing shape of the probability weighting function in the population is inverse S-shaped (Kahneman and Tversky 1979; Wu and Gonzalez 1996; Fehr-Duda et al. 2006), linear (Hey and Orme 1994) or convex (Jullien and Salanié 2000; Goeree et al. 2002; van de Kuilen and Wakker 2009).

The data that are used in this study are obtained from a large representative internet survey that consists of 27 matching questions per individual. In order to reduce the dependence on functional form assumptions, we use a three-stage estimation procedure that exploits the (gamble-) trade-off method for the elicitation of utilities. This method is robust against subjective probability distortion (Wakker and Deneffe 1996) such that the measurement of utility does not depend on the estimates of the probability weights. Our stochastic specification allows for decision errors, and it naturally accommodates the propagation of errors that is introduced by the chaining of the questions that is at the heart the trade-off method (Blavatskyy 2006). Furthermore, the data contains background variables that can be linked to the obtained preference 
parameters to shed light on how the various components of risk attitudes vary in the population. Finally, a randomly assigned scaling-up of the outcomes by a factor 10 allows us to test whether utility curvature and probability weighting are sensitive to the magnitude of the stakes (Etchart-Vincent 2004).

The analysis confirms and complements the study of Booij and van de Kuilen (2007), who present non-parametric estimates of utility curvature and loss aversion obtained from a subset of the same data. The results reiterate their main finding that utility curvature is close to linear and much less pronounced than suggested by classical utility measurements that neglect probability weighting. Diminishing sensitivity is also found, as predicted by prospect theory but contrary to the classical prediction of universal concavity. Utility for gains and losses is found to be closer to linear compared to other parametric studies, suggesting these may be misspecified, while our results are a little more curved compared to the non-parametric estimates. This suggests that assuming homogeneity leads to a small downward bias, while providing evidence that error propagation is unlikely to greatly affect the results in the non-parametric analysis. In addition, we find evidence of an inverted-S shaped probability weighting function that is more elevated for losses than for gains, suggesting pessimism in both domains. We do not find evidence that the shape or the degree of elevation of the probability weighting functions depend on the magnitude of the stakes; however, the weighting function for gains varies with gender and age. The weighting function for losses seems unrelated to any background variables. These results confirm the common finding that females are more risk averse than males; however, but contrary to classical studies that ascribed this gender difference solely to differences in the degree of utility curvature, our results show that this finding is primarily driven by subjective probability weighting and loss aversion.

The remainder of this article is organized as follows. Section 2 discusses prospect theory and summarizes the parametric estimates found in the literature. Section 3 presents the experimental method and summary statistics of the data, followed by the presentation of the econometric specification in Sect. 4. The results are presented in Sect. 5. Section 6 concludes, followed by the appendix that provides estimates of sample selection.

\section{Prospect theory}

\subsection{The model}

We consider decision under risk, with $\mathbb{R}$ the set of possible monetary outcomes of gains and losses with respect to some wealth level or reference point. The reference point is assumed to be the status quo, i.e., the current wealth level. A prospect is a finite probability distribution over outcomes. Thus, a prospect yielding outcome $x_{i}$ with probability $p_{i}(i=1, \ldots, n)$ is denoted by $\left(p_{1}: x_{1}, \ldots, p_{n}: x_{n}\right)$. A two-outcome prospect $(p: x, 1-p: y)$ is denoted by $(p: x, y)$ and the unit of payment for outcomes is 1 Euro. In this article, prospect theory refers to the modern (cumulative) version of prospect theory introduced by Tversky and Kahneman (1992), that corrected the original 1979 version for violations of stochastic dominance and, more importantly, can also 
deal with uncertainty, i.e., the case of unknown probabilities. Prospect theory entails that the value of a prospect with outcomes $x_{1} \leq \cdots \leq x_{k} \leq 0 \leq x_{k+1} \leq \cdots \leq x_{n}$ is given by:

$$
\sum_{i=1}^{k} \pi_{i}^{-} \mathrm{U}\left(x_{i}\right)+\sum_{j=k+1}^{n} \pi_{j}^{+} \mathrm{U}\left(x_{j}\right) .
$$

Here $U: \mathbb{R} \rightarrow \mathbb{R}$ is a continuous and strictly increasing utility function satisfying $\mathrm{U}(0)=0$, and $\pi^{+}$and $\pi^{-}$are the decision weights, for gains and losses, respectively, defined by

$$
\begin{aligned}
& \pi_{1}^{-}=w^{-}\left(p_{1}\right), \quad \pi_{n}^{+}=w^{+}\left(p_{n}\right) \\
& \pi_{i}^{-}=w^{-}\left(p_{1}+\cdots+p_{i}\right)-w^{-}\left(p_{1}+\cdots+p_{i-1}\right) \quad \text { for } 1<i \leq k, \text { and } \\
& \pi_{j}^{+}=w^{+}\left(p_{j}+\cdots+p_{n}\right)-w^{+}\left(p_{j+1}+\cdots+p_{n}\right) \text { for } k<j<n .
\end{aligned}
$$

Here $w^{+}$is the probability weighting function for gains and $w^{-}$is the probability weighting function for losses, satisfying $w^{+}(0)=w^{-}(0)=0$ and $w^{+}(1)=w^{-}(1)=$ 1 , and both strictly increasing and continuous. Thus, the decision weight of a positive outcome $x_{i}$ is the marginal $w^{+}$contribution of $p_{i}$ to the probability of receiving better outcomes, and the decision weight of a negative outcome $x_{i}$ is the marginal $w^{-}$ contribution of $p_{i}$ to the probability of receiving worse outcomes. Finally, note that the decision weights do not necessarily add up to 1 and that prospect theory coincides with expected utility if people do not distort probabilities (i.e., $w^{+}$and $w^{-}$are the identity) and individuals use a fixed reference point in terms of wealth. ${ }^{2}$

\subsection{Parametric specifications}

To make the model empirically tractable, several parametric shapes have been proposed for the utility- and probability weighting functions. The utility function determines individuals' attitudes toward additional monetary gains and losses. The curvature of this function for gains is often modeled by a power function because of its simplicity and its good fit to (experimental) data (Wakker 2008). ${ }^{3}$ Tversky and Kahneman (1992) introduced this function for prospect theory, written as $\mathrm{U}(x)=x^{\alpha} 1(x \geq$ $0)-\lambda(-x)^{\beta} 1(x<0)$. Here, the parameters $\alpha$ and $\beta$ determine the curvature of the utility for money gains and losses, respectively. The psychological concept of diminishing sensitivity implies that both $\alpha<1$ and $\beta<1$, i.e., individuals are decreasingly

\footnotetext{
2 There is a debate in the literature on whether the expected utility model presupposes that outcomes are defined in terms of final wealth (which precludes reference-dependence) or not. In this article, we consider expected utility to be defined over wealth (Wakker 2005). See Cox and Sadiraj (2006) and Rubinstein (2006) for an alternative interpretation of expected utility.

${ }^{3}$ Under expected utility, this function implies that an agent is prepared to pay a constant fraction of wealth to avoid risking a fair gamble over percentages of wealth. For this reason, the power function is commonly referred to as constant relative risk aversion (CRRA). Under non-expected utility models such as prospect theory, this designation is no longer appropriate.
} 
sensitive to changes further away from the reference point. Less frequently used parametric specifications of the utility function are the exponential and the expo-power utility functions. These functions often have a slightly inferior fit. Their properties are described extensively in Abdellaoui et al. (2007a).

Unfortunately, a commonly accepted definition of loss aversion does not exist in the literature (Abdellaoui et al. 2007b). The framework that we employ, used by Tversky and Kahneman (1992), defines loss aversion implicitly as:

$$
\lambda=-\frac{u(-1)}{u(1)} .
$$

This definition can be seen as an approximation of the definition proposed by Köbberling and Wakker (2005), who characterize loss aversion as the ratio between the left and right derivatives of the utility function at zero, i.e., $\lambda^{K W} \equiv u_{\uparrow}^{\prime}(0) / u_{\downarrow}^{\prime}(0)$. Other definitions that have been proposed, such as Kahneman and Tversky's original formulation of loss aversion as $-u(-x)>u(x)$ for all $x>0$, or a stronger version formulated by Wakker and Tversky (1993) given by $u^{\prime}(-x)>u^{\prime}(x)$ for all $x>0$, do not define a straight index of loss aversion but formulate it as a property of the utility function over a whole range. An index can then be constructed by taking the mean or median values of the relevant values of $x$, but this is not an arbitrary choice making comparison between measurements difficult. Hence, we have to be careful with comparing loss aversion estimates (see Abdellaoui et al. (2007b) for a more extensive discussion).

The probability weighting function captures the degree of sensitivity toward probabilities. Two distinct properties of this function have been put forward, that can be given a psychological interpretation. The first property refers to the degree of curvature of the probability weighting function, which reflects the degree of discriminability with respect to changes in probabilities. This property is closely linked to the notion of diminishing sensitivity, where the probability of 0 (impossibility) and 1 (certainty) serve as reference points. According to this psychological hypothesis, people's behavior becomes less responsive to changes on the probability scale as they move further away from these reference points. This implies an inverse-S shaped weighting function, with relatively much curvature near the probability end points and a linear shape in between. The second property of the probability weighting function refers to its elevation, which determines the degree of attractiveness of gambling (Gonzalez and $\mathrm{Wu}$ 1999). For gains (losses), a highly elevated probability weighting function implies that individuals are optimistic (pessimistic), and overweight probabilities relative to the objective probabilities of gaining (losing).

Several parametric functions have been proposed to describe the probably weighting function (see Stott 2006 for an overview). The most commonly used specification is the linear-in-log-odds specification, introduced by Goldstein and Einhorn (1987) (GE-87), and given by:

$$
w(p)=\delta p^{\gamma} /\left(\delta p^{\gamma}+(1-p)^{\gamma}\right) .
$$


The popularity of this function stems from its empirical tractability and the fact that it has two parameters, $\gamma$ and $\delta$, that separately control for curvature and elevation, respectively. Hence, both parameters can readily be given a psychological interpretation as indexes of discriminability and attractiveness. Another popular specification in which $\gamma$ and $\delta$ have a similar interpretation is the two-parameter specification proposed by Prelec (1998) (Prelec-2), given by:

$$
w(p)=\exp \left(-\delta(-\ln p)^{\gamma}\right)
$$

The GE-87 specification has an inverted-S shape when $0<\gamma<1$. An additional (sufficient) condition for the Prelec-2 function is $0<\delta<1$. One-parameter specifications have also been used to describe the probability weighting function, but these cannot set curvature and elevation independently. Estimates of these probability weighting functions will lead to biased inferences if curvature and elevation do not co-vary accordingly.

\subsection{Empirical evidence}

Table 1 gives the definition and estimates of the power utility function and some commonly used one- and two-parameter probability weighting functions. All the mentioned studies estimate prospect theory, albeit with varying (parametric) assumptions, incentives, tasks, and samples. Although the table is not intended to be exhaustive, it covers most studies that somehow report a parametric measure of utility curvature, loss aversion, or probability weighting under prospect theory. Studies that do not report such estimates are not included in the table, which means that not all the studies mentioned in the introduction are listed. If multiple measures of loss aversion are reported, we take the definition that most closely resembles that of Köbberling and Wakker (2005).

With respect to the shape of the utility function, the table reveals four notable features. First of all, the utility for gains is much closer to linearity (a power equal to 1) than what is found in classical utility measurements that do not take probability weighting into account. In that literature, estimates just below .5 (Cubitt et al. 2001; Holt and Laury 2002; Harrison et al. 2005; Andersen et al. 2008) or lower (Barsky et al. 1997; Dohmen et al. 2006) are common. Second, in all the studies that report utility curvature for gains and losses, losses are evaluated more linearly than gains, but utility for losses does display diminishing sensitivity $(\beta<1)$ in most studies. This suggests that people become less sensitive toward additional gains more rapidly as compared to additional losses. Third, there is some variability in the estimates, but the power parameters for both domains are always quite close. This suggests that the differences in the estimates between studies most likely stem from differences in the elicitation method and the method of analysis. Fourth, there is significant variation in the coefficient of loss aversion, but it is always estimated to be higher than one.

The table conveys three other notable features with respect to the estimated shape of the probability weighting function. The predominant shape is inverse-S, with few studies reporting $\gamma>1$. Also, for studies that report estimates of both domains, elevation 
Table 1 Empirical estimates of prospect theory using different parametric functionals

\begin{tabular}{|c|c|c|c|c|c|c|c|c|c|}
\hline \multirow{2}{*}{$\begin{array}{l}\text { Functional form } \\
\text { Utility }\end{array}$} & \multicolumn{3}{|c|}{ Estimates } & & \multicolumn{4}{|c|}{ Properties** } & \multirow[t]{2}{*}{ Authors } \\
\hline & $\alpha$ & $\beta$ & $\lambda$ & & E. & $\mathrm{T}$ & I & $\mathrm{N}$ & \\
\hline \multirow{16}{*}{$\begin{array}{l}\text { Power: } \\
\quad * \mathrm{U}(x)= \\
x^{\alpha 1}(x \geq 0)- \\
\lambda(-x)^{\beta 1}(x<0)\end{array}$} & .88 & .88 & 2.25 & & md & $\mathrm{c}$ & $\mathrm{n}$ & 25 & Tversky and Kahneman (1992) \\
\hline & .22 & & & & $\mathrm{ml}$ & $\mathrm{c}$ & $\mathrm{n}$ & 1497 & Camerer and Ho (1994) \\
\hline & .50 & & & & $\mathrm{ml}$ & $\mathrm{c}$ & $\mathrm{n}$ & 420 & Wu and Gonzalez (1996) \\
\hline & .39 & .84 & & & md & $\mathrm{c}$ & $\mathrm{n}$ & 64 & Fennema and van Assen (1998) \\
\hline & .49 & & & & md & $\mathrm{c}$ & $\mathrm{y}$ & 10 & Gonzalez and Wu (1999) \\
\hline & .89 & .92 & & & md & $\mathrm{c}$ & $\mathrm{y}$ & 40 & Abdellaoui (2000) \\
\hline & .61 & 61 & & & $\mathrm{ml}$ & $\mathrm{b}$ & $\mathrm{n}$ & 2593 & Donkers et al. (2001) \\
\hline & & & 1.43 & & md & $\mathrm{c}$ & $\mathrm{n}$ & 45 & Schmidt and Traub (2002) \\
\hline & & .97 & & & md & $\mathrm{c}$ & $\mathrm{n}$ & 35 & Etchart-Vincent (2004) \\
\hline & .91 & .96 & & & md & $\mathrm{c}$ & $\mathrm{n}$ & 41 & Abdellaoui et al. (2005) \\
\hline & .68 & .74 & 3.2 & & $\mathrm{ml}$ & $\mathrm{b}$ & $\mathrm{n}$ & 1743 & $\mathrm{Tu}(2005)$ \\
\hline & 1.01 & 1.05 & & & md & $\mathrm{c}$ & $\mathrm{y}$ & 181 & Fehr-Duda et al. (2006) \\
\hline & .72 & .73 & 2.54 & & md & $\mathrm{c}$ & $\mathrm{n}$ & 48 & Abdellaoui et al. (2007b) \\
\hline & .81 & .80 & 1.07 & & $\mathrm{ml}$ & $\mathrm{c}$ & $\mathrm{y}$ & 90 & Andersen et al. (2006) \\
\hline & .71 & .72 & 1.38 & & $\mathrm{ml}$ & $\mathrm{c}$ & $\mathrm{y}$ & 158 & Harrison and Rutström (2009) \\
\hline & .86 & 1.06 & 2.61 & & md & $\mathrm{c}$ & $\mathrm{y}$ & 48 & Abdellaoui et al. (2008) \\
\hline Probability weights. & $\delta^{+}$ & $\gamma^{+}$ & $\delta^{-}$ & $\gamma^{-}$ & & & & & \\
\hline \multirow{8}{*}{$\begin{array}{l}\text { TK-92: } \\
\qquad \begin{array}{c}w(p)= \\
p^{\gamma}\end{array} \\
{\left[p^{\gamma}+(1-p\right.}\end{array}$} & & .61 & & .69 & & $\mathrm{c}$ & $\mathrm{n}$ & 25 & Tversky and Kahneman (1992) \\
\hline & & & & & & & & & \\
\hline & & .56 & & & & $\mathrm{c}$ & $\mathrm{n}$ & 1497 & Camerer and Ho (1994) \\
\hline & & .71 & & & & $\mathrm{c}$ & $\mathrm{n}$ & 420 & Wu and Gonzalez (1996) \\
\hline & & .60 & & .70 & & $\mathrm{c}$ & $\mathrm{y}$ & 40 & Abdellaoui (2000) \\
\hline & & .67 & & & & $\mathrm{~m}$ & $\mathrm{n}$ & 51 & Bleichrodt and Pinto (2000) \\
\hline & & .76 & & .76 & & $\mathrm{c}$ & $\mathrm{y}$ & 90 & Andersen et al. (2006) \\
\hline & & .91 & & .91 & & $\mathrm{c}$ & $\mathrm{y}$ & 158 & Harrison and Rutström (2009) \\
\hline \multirow[t]{8}{*}{$\begin{array}{l}\text { GE-87: } \\
\begin{array}{l}w(p)= \\
\frac{\delta p^{\gamma}}{\delta p^{\gamma}+(1-p)^{\gamma}}\end{array}\end{array}$} & .84 & .68 & & & & $\mathrm{c}$ & $\mathrm{n}$ & 420 & Wu and Gonzalez (1996) \\
\hline & .77 & 69 & & & md & $\mathrm{c}$ & $\mathrm{n}$ & 40 & Tversky and Fox (1995) \\
\hline & .77 & .44 & & & & $\mathrm{c}$ & $\mathrm{y}$ & 10 & Gonzalez and Wu (1999) \\
\hline & .65 & .60 & .84 & .65 & & $\mathrm{c}$ & $\mathrm{y}$ & 40 & Abdellaoui (2000) \\
\hline & .82 & .55 & & & & $\mathrm{~m}$ & $\mathrm{n}$ & 51 & Bleichrodt and Pinto (2000) \\
\hline & & & 1.10 & .84 & & $\mathrm{c}$ & $\mathrm{n}$ & 35 & Etchart-Vincent (2004) \\
\hline & .98 & .83 & 1.35 & .84 & & $\mathrm{c}$ & $\mathrm{n}$ & 41 & Abdellaoui et al. (2005) \\
\hline & .87 & .51 & 1.07 & .53 & & $\mathrm{c}$ & $\mathrm{y}$ & 181 & Fehr-Duda et al. (2006) \\
\hline \multicolumn{10}{|l|}{$\begin{array}{l}\text { Prelec-1: } \\
w(p)= \\
\exp \left(-(-\ln p)^{\gamma}\right)\end{array}$} \\
\hline & & .74 & & & & $\mathrm{c}$ & $\mathrm{n}$ & 420 & Wu and Gonzalez (1996) \\
\hline & & .53 & & & & $\mathrm{~m}$ & $\mathrm{n}$ & 51 & Bleichrodt and Pinto (2000) \\
\hline & & .413 & & .413 & & $\mathrm{~b}$ & $\mathrm{n}$ & 2593 & Donkers et al. (2001) \\
\hline & & 1.00 & & .77 & & $\mathrm{~b}$ & $\mathrm{n}$ & 1743 & $\mathrm{Tu}(2005)$ \\
\hline
\end{tabular}


Table 1 continued

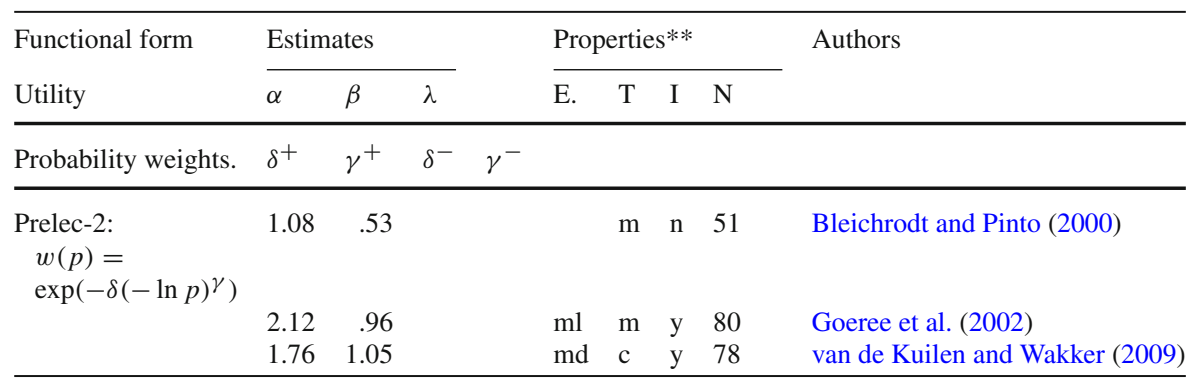

Notes: Adopted names and notations do not form a convention, and are used for convenience. +/- denote gains/losses

* The utility functional is specified on the complete real axis, where $\lambda$ represents the loss-aversion coefficient. The displayed utility function is based on the assumption $\alpha>0$ and $\beta>0$, which is mostly found empirically. The function has a different specification for other parameter values (Wakker 2008)

** Properties: E(estimator): mean; median $(m d)$; maximum likelihood $(m l)$; T(task): choice; matching; $b$ oth; I(incentives): $y$ es (random lottery incentive scheme/Becker de Groot-Marschak procedure); no (fixed or no payment)

is higher in the loss domain. This is intuitively plausible because it suggests that in both domains individuals display pessimism, i.e., they dislike gambling. Finally, the estimates of elevation show a little less variability than those of curvature, suggesting that curvature is harder to identify empirically.

The coefficients of loss aversion reported in Table 1 range from 1.07 to 3.2. Hence, all the studies find evidence of loss aversion, albeit to varying degrees. This may be caused by differing definitions of loss aversion and different elicitation contexts. Figure 1 plots a power utility function and a GE-87 probability weighting function for gains and losses corresponding to the average of the estimates found in Table 1 . The next section describes the data that will enable us to identify utility curvature and probability weighting for a representative sample.

\section{The data}

\subsection{Survey design}

\subsubsection{Participants}

For the elicitation of both utility curvature and subjective probability weighting, we used data collected through the CentERpanel, a representative panel consisting of about 2000 Dutch households. Every weekend, the participants of this panel complete an internet-questionnaire concerning various socio-economic and psychological questions. For those households that do not own a computer with a connection to the internet, a special box connected to the television is provided. The panel has been used by many researchers because of its representative nature, randomization possibilities, and the possibility to link the obtained data to background characteristics. 

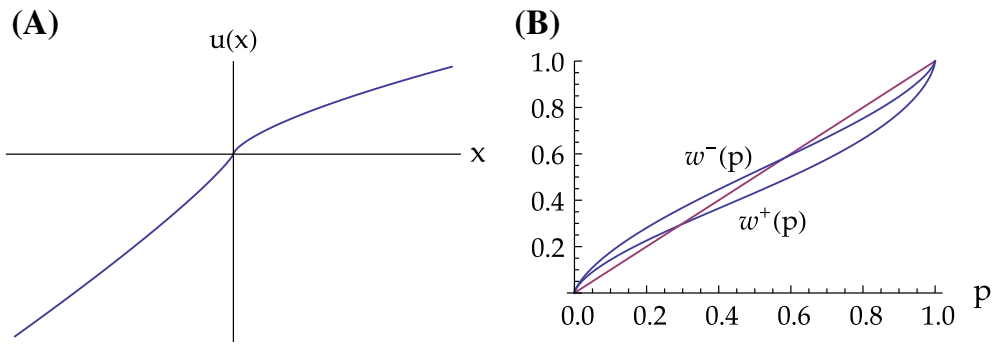

Fig. 1 Utility and probability weighting functions for average estimates. Note: Figure based on the average of the estimates from Table $1 .(\alpha, \beta, \lambda)=(.69, .86,2.07)$ and $\left(\delta^{+}, \gamma^{+}, \delta^{-}, \gamma^{-}\right)=(.76, .69,1.09, .72)$

\subsubsection{Procedure}

In February 2006, the participants of the panel were asked to balance a total of 27 pairs of (hypothetical) two-outcome lotteries by stating the value that would make them indifferent between the lotteries in the pair. The respondents were given extensive experimental instructions ${ }^{4}$ and were then asked to answer a practice question to familiarize them with the experimental setting. In the instructions, it was emphasized that there were no right or wrong answers. In the first part of the questionnaire (Q1Q16), indifference was obtained through outcome matching, i.e., in Fig. 2a, subjects were asked to report the (missing) euro amount that would make them indifferent between the two lotteries, where the parameters $\left(L_{2}, R_{1}, R_{2}\right)$ differed between questions. The wheel in the middle served to explain probabilities to respondents. In the second part (Q17-Q27), indifference was obtained through probability matching, i.e., in Fig. 2b, subjects were asked to report the (missing) probability that would make them indifferent between the two lotteries, where again the parameters $\left(L_{2}, R_{1}, R_{2}\right)$ differed between questions. After filling in a specific number, the areas in the wheel were filled accordingly, and the respondent was asked to confirm his choice or reconsider.

\subsubsection{First Part}

Table 2 gives a complete description of the structure of the survey questions. According to Wakker and Deneffe (1996), the questions in the first part were chained, where the answer $x_{i}$ that was given to one question, was used as the upper right prize in the next question, holding the other prizes constant $\left(L_{2}=g, R_{2}=G\right)$. For example, if a subject reported an indifference value $\underline{x}_{1}=€ 180$ for the prospects $\left(0.5: \underline{x}_{1}, € 12\right)$ and (0.5: $€ 100, € 64)$, this number appeared as the upper prize of the right prospect of the next matching question, while the alternative prizes of both lotteries remained the same: $\left(0.5: \underline{x}_{2}, € 12\right) \sim(0.5: € 180, € 64)$. The answer $\underline{x}_{2}$ was then used in the next question and so on. The first set of six questions following the practice question (Q2-Q7) concern a sequence of gains $x_{1}, \ldots, x_{6}$, followed by a set of six questions (Q8-Q13) that entail losses $y_{1}, \ldots, y_{6}\left(L_{2}=l, R_{2}=L\right)$.

\footnotetext{
${ }^{4}$ Available from the authors upon request.
} 
(A) LottrRY L

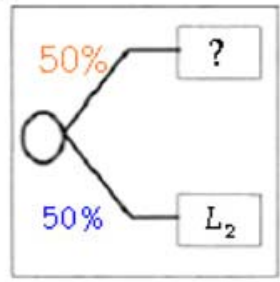

(B)

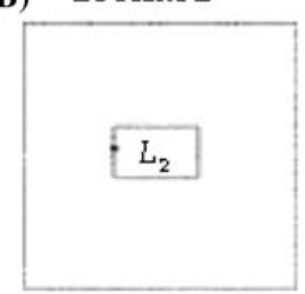

WHEEI

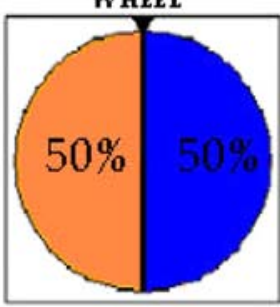

WHEEI

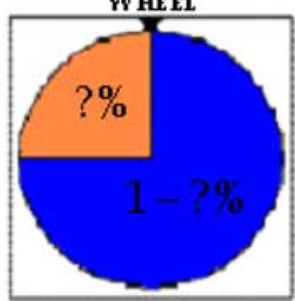

LOTTERY R

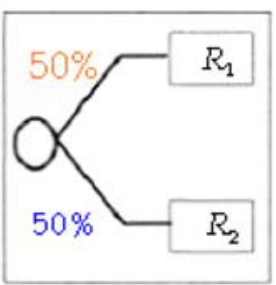

LO TTERY R

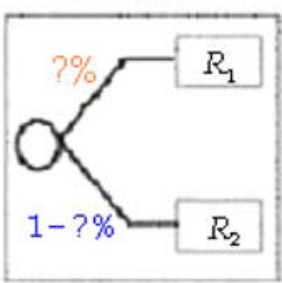

Fig. 2 The framing of the prospect pairs. Note: Frame $\mathbf{a}$ above and $\mathbf{b}$ below. The specific parameter values varied between the questions, see Table 2

Table 2 The obtained indifferences

\begin{tabular}{|c|c|c|c|c|c|c|c|}
\hline $\begin{array}{l}\text { Question } \\
\text { Part I }\end{array}$ & $\begin{array}{l}\text { Prospect L } \\
\left(p: L_{1}, L_{2}\right)\end{array}$ & & $\begin{array}{l}\text { Prospect R } \\
\left(p: R_{1}, R_{2}\right)\end{array}$ & $\begin{array}{l}\text { Question } \\
\text { Part II }\end{array}$ & $\begin{array}{l}\text { Prospect L } \\
\left(L_{2}\right)\end{array}$ & & $\begin{array}{l}\text { Prospect R } \\
\left(p: R_{1}, R_{2}\right)\end{array}$ \\
\hline 1 (practice) & $(0.5: \underline{a}, 10)$ & $\sim$ & $(0.5: 50,20)$ & 17 (practice) & $(250)$ & $\sim$ & $(\underline{\mathrm{r}}: 750,-100)$ \\
\hline 2 (gains) & $\left(0.5: \underline{x}_{1}, g\right)$ & $\sim$ & $\left(0.5: x_{0}, G\right)$ & $18 * *$ & $\left(x_{1}\right)$ & $\sim$ & $\left(\underline{p}_{1}: x_{6}, x_{0}\right)$ \\
\hline 3 (gains) & $\left(0.5: \underline{x}_{2}, g\right)$ & $\sim$ & $\left(0.5: x_{1}, G\right)$ & $19 * *$ & $\left(y_{1}\right)$ & $\sim$ & $\left(\underline{q}_{1}: y_{6}, y_{0}\right)$ \\
\hline 4 (gains) & $\left(0.5: \underline{x}_{3}, g\right)$ & $\sim$ & $\left(0.5: x_{2}, G\right)$ & $20 * *$ & $\left(x_{2}\right)$ & $\sim$ & $\left(\underline{p}_{2}: x_{6}, x_{0}\right)$ \\
\hline 5 (gains) & $\left(0.5: \underline{x}_{4}, g\right)$ & $\sim$ & $\left(0.5: x_{3}, G\right)$ & $21 * *$ & $\left(y_{2}\right)$ & $\sim$ & $\left(\underline{q_{2}}: y_{6}, y_{0}\right)$ \\
\hline 6 (gains) & $\left(0.5: \underline{x}_{5}, g\right)$ & $\sim$ & $\left(0.5: x_{4}, G\right)$ & $22 * *$ & $\left(x_{3}\right)$ & $\sim$ & $\left(\underline{p}_{3}: x_{6}, x_{0}\right)$ \\
\hline 7 (gains) & $\left(0.5: \underline{x}_{6}, g\right)$ & $\sim$ & $\left(0.5: x_{5}, G\right)$ & $23 * *$ & $\left(y_{3}\right)$ & $\sim$ & $\left(\underline{q_{3}}: y_{6}, y_{0}\right)$ \\
\hline 8 (losses) & $\left(0.5: \underline{y}_{1}, l\right)$ & $\sim$ & $\left(0.5: y_{0}, L\right)$ & $24 * *$ & $\left(x_{4}\right)$ & $\sim$ & $\left(\underline{p}_{4}: x_{6}, x_{0}\right)$ \\
\hline 9 (losses) & $\left(0.5: \underline{y}_{2}, l\right)$ & $\sim$ & $\left(0.5: y_{1}, L\right)$ & $25^{* *}$ & $\left(y_{4}\right)$ & $\sim$ & $\left(\underline{q}_{4}: y_{6}, y_{0}\right)$ \\
\hline 10 (losses) & $\left(0.5: \underline{y}_{3}, l\right)$ & $\sim$ & $\left(0.5: y_{2}, L\right)$ & $26^{* * *}$ & $\left(x_{5}\right)$ & $\sim$ & $\left(p_{5}: x_{6}, x_{0}\right)$ \\
\hline 11 (losses) & $\left(0.5: \underline{y}_{4}, l\right)$ & $\sim$ & $\left(0.5: y_{3}, L\right)$ & $27 * *$ & $\left(y_{5}\right)$ & $\sim$ & $\left(q_{5}: y_{6}, y_{0}\right)$ \\
\hline 12 (losses) & $\left(0.5: \underline{y}_{5}, l\right)$ & $\sim$ & $\left(0.5: y_{4}, L\right)$ & & & & \\
\hline 13 (losses) & $\left(0.5: \underline{y}_{6}, l\right)$ & $\sim$ & $\left(0.5: y_{5}, L\right)$ & & & & \\
\hline $14 *$ (gains) & $(0.5: \underline{b}, 0)$ & $\sim$ & $\left(0.5: x_{1}, x_{0}\right)$ & & & & \\
\hline $15^{*}$ (losses) & $(0.5: 0, \underline{c})$ & $\sim$ & $\left(0.5: y_{0}, y_{1}\right)$ & & & & \\
\hline $16^{*}$ (mixed) & $\left(0.5: \underline{d}, y_{1}\right)$ & $\sim$ & $\left(0.5: x_{0}, y_{0}\right)$ & & & & \\
\hline
\end{tabular}

Note: Underlined outcomes are the matching outcomes/probabilities, and questions marked with an asterisk were presented in randomized order

Under prospect theory, it can be shown that the outcomes of the obtained sequences are equally spaced in terms of utility. Wakker and Deneffe (1996) named such a 
sequence a standard sequence of outcomes. The final three questions of the first part (Q14-Q16) give additional information on utility curvature around the zero outcome and allow for the determination of loss aversion. ${ }^{5}$

\subsubsection{Second Part}

The questions of the second part allow for the non-parametric determination of the subjective probability weighting functions at the individual level if one assumes that no stochastic errors have been made in the elicitation of the indifference outcomes $\left(x_{1}, \ldots, x_{6}, y_{1}, \ldots, y_{6}\right)$ in the first part. To see this, consider the domain of gains and assume that there is no stochastic error component in the subjects' responses. Then, under prospect theory, the reported probabilities $p_{i}$ satisfy $w\left(p_{i}\right)=$ $\left(\left(\mathrm{U}\left(x_{i}\right)-\mathrm{U}\left(x_{0}\right)\right) /\left(\left(\mathrm{U}\left(x_{6}\right)-\mathrm{U}\left(x_{0}\right)\right)\right.\right.$. Given that the outcomes $x_{0}, \ldots, x_{6}$ comprise a standard sequence of outcomes, there holds $\mathrm{U}\left(x_{i}\right)-\mathrm{U}\left(x_{i}\right)=\mathrm{U}\left(x_{i+1}\right)-\mathrm{U}\left(x_{i}\right)$ for $i=1, \ldots, 5$. This implies that $\left(\left(\mathrm{U}\left(x_{i}\right)-\mathrm{U}\left(x_{0}\right)\right) /\left(\left(\mathrm{U}\left(x_{6}\right)-\mathrm{U}\left(x_{0}\right)\right)=i / 6\right.\right.$, and hence $w\left(p_{i}\right)=i / 6$ (Abdellaoui 2000). In the presence of error, however, this correspondence need no longer hold because the outcomes $x_{0}, \ldots, x_{6}$, are then, in general, not equally spaced in utility units. The econometric specification we use explicitly accounts for this in the analysis of the responses to these questions.

\subsubsection{Treatments}

In order to test whether the elicited shapes of prospect theory's functionals are sensitive to the size of the stakes, respondents were randomly assigned to two different treatments. In the low-stimuli treatment the parameter values were set at $G=64, g=$ $12, x_{0}=100, L=-32, l=-6$, and $y_{0}=-50$. In the high-stimuli treatment, all parameter values were scaled up by a factor 10 .

\subsection{Summary statistics}

A total of 1,935 individuals responded to the survey, meaning they logged in to the site with their ID number. Not all the subjects gave answers to all the questions, leading to question-specific non-response (denoted by $N R$ ). Since we did not force subjects' answers to be consistent (the subjects could fill in any number) it comes as no surprise that many of them violated dominance, either because of a mistake or because of misunderstanding (denoted by $I R$ ). In the first part, individuals were classified as being inconsistent if their sequence of stated outcomes was not strictly increasing. This criterion is stringent, punishing random mistakes. For those who comply with it, however, we can be confident that they understood the questions.

Contrary to the outcome questions, the order of the probability matching questions was completely random, meaning that subjects could not have an easy comparison with questions that had outcomes close in magnitude. This increases the likelihood of an inconsistent answer. Moreover, these questions are likely to be more cognitively

\footnotetext{
5 See Booij and van de Kuilen (2007) for a more detailed description of the structure of these questions.
} 
demanding for respondents. Hence, in part 2, we allowed for one mistake (meaning a violation of dominance) in the subjects' answers before classifying them as inconsistent. Furthermore, we only considered individuals in the second part if they had been classified consistent in the first, because the questions in the second part were determined by the first. Of the remaining data, we removed some outlying answers that clearly indicated either a mistake or lack of understanding (denoted by Outlier).

Although dropping observations is unfavorable, not imposing consistency by way of the design of the experiment (recall that the subjects were free to fill in any number) has some advantages, especially when using a large representative sample. Then, individuals with a good understanding of the questions can reveal themselves by not making any mistakes. Indeed, there is evidence for university students showing response variability increases with the complexity of the task (Camerer and Hogarth 1999). For the general public this effect is probably magnified. Using the same internet panel Von Gaudecker et al. (2008) specifically investigate sample selection for a cognitively demanding (risk aversion) task, and find that the number of inconsistencies is twice as large for the general public compared to the standard student subject pool. Similarly, Guiso and Paiella (2003) and Dohmen et al. (2006) dropped 57\% and 61\% of their observations, respectively, for risk aversion questions of lesser complexity posed to a cross section of the Italian and German public. Hence, miscomprehension is a likely feature of response behavior in our data. Not imposing consistency by design of the experiment allows the filtering of those who did not have a good grasp of the questions from those who did.

In order to control for a potential bias due to selectivity we estimated a sampleselection equation (see Sect. 7.1) and used the inverse of the predicted probabilities as weights in the econometric analysis. This procedure yields unbiased estimates if sample selection is random conditional on the selection variables. The coefficients were not greatly affected by this procedure, but it increased the obtained standard errors. Hence, we are confident that the results obtained from the selected sample hold for the whole sample as well. Booij and van de Kuilen (2007) discuss the sample selection process in more detail. Table 3 gives the summary statistics of the selected sample.

The table readily shows some apparent features of the data. The differences between subsequent outcomes of the standard sequence are gradually increasing, suggesting mild concavity in the utility for gains and mild convexity for losses. Also, the probabilities reported in the gain domain are all uniformly higher than the those in the loss domain suggesting more elevation in the probability weighting function for losses. This is consistent with pessimism with respect to gambling in both domains. Finally, the outcomes between the high and the low treatments are mostly close to a scaling up by a factor 10 , suggesting no difference between treatments.

\section{The econometric model}

Following Wakker and Deneffe (1996) and Abdellaoui (2000), Booij and van de Kuilen (2007) exploit the sequential nature of the questions to analyze the shape of the utility function non-parametrically. This approach has the advantage of being robust against probability weighting and allowing for full heterogeneity in preferences, i.e., they 


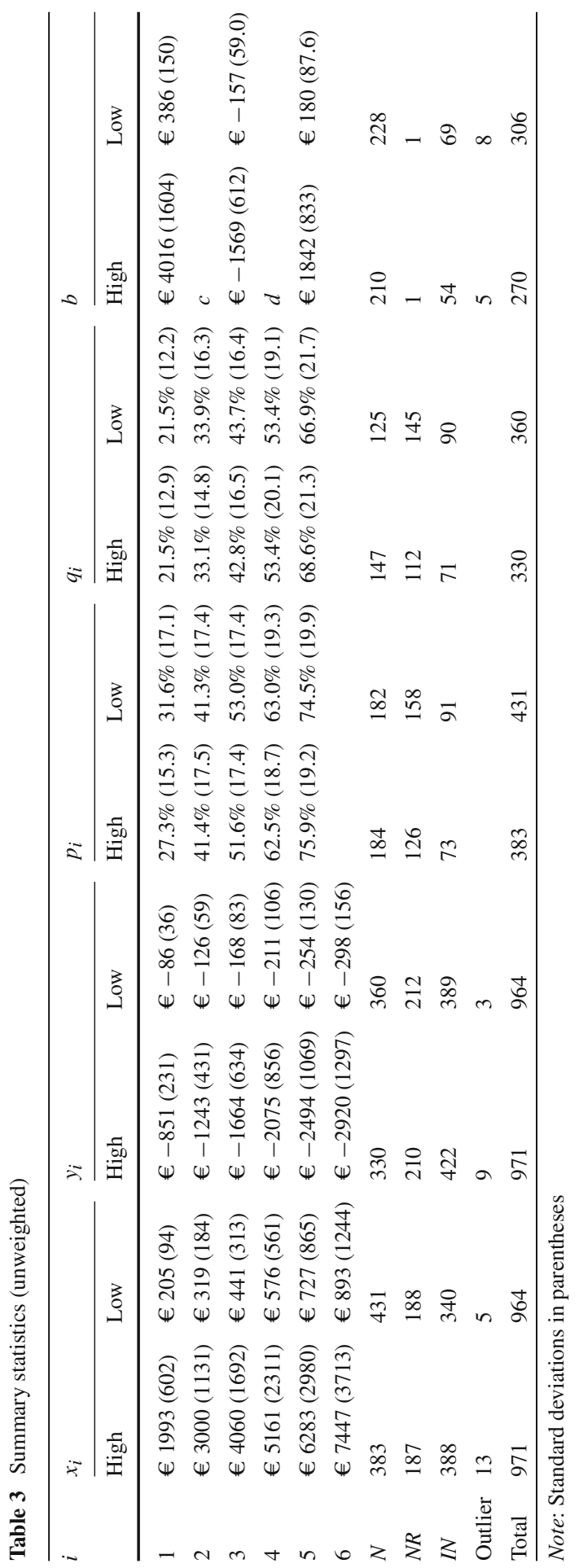


estimate the shape of the utility curve for each individual without making any prior parametric assumption. The disadvantage of this approach is that individual error is not explicitly accounted for statistically, and potential error propagation is not modeled. Also, if errors that generate monotonicity violations are not modeled in the analysis of the elicited probabilities in the second part (recall that we allow for one monotonicity violation in the second part), we would get uninterpretable weighting functions. Moreover, Wilcox (2008, pp. 264-265) shows that individual level estimation can suffer from a finite-sample bias leading to biased predictions. By smoothing out errors, a parametric approach can alleviate these problems (Currim and Sarin 1989), albeit at the cost of having to make auxiliary assumptions.

Under prospect theory, as described in section 2.1, the questions in the experiment yield the following equations

$$
\begin{aligned}
w^{+}\left(\frac{1}{2}\right)\left(\mathrm{U}\left(x_{i, n}\right)-\mathrm{U}\left(x_{i-1, n}\right)\right)= & \left(1-w^{+}\left(\frac{1}{2}\right)\right)\left(\mathrm{U}\left(G_{n}\right)\right. \\
& \left.-\mathrm{U}\left(g_{n}\right)\right) \cdot e_{i, n}^{o+} \cdot \eta_{n}^{+} \quad i=1, \ldots, 6, \\
w^{-}\left(\frac{1}{2}\right)\left(\mathrm{U}\left(y_{i, n}\right)-\mathrm{U}\left(y_{i-1, n}\right)\right)= & \left(1-w^{-}\left(\frac{1}{2}\right)\right)\left(\mathrm{U}\left(L_{n}\right)\right. \\
& \left.-\mathrm{U}\left(l_{n}\right)\right) \cdot e_{i, n}^{o-} \cdot \eta_{n}^{-} \quad i=1, \ldots, 6, \\
\mathrm{U}\left(x_{i, n}\right)-\mathrm{U}\left(x_{0, n}\right)= & w^{+}\left(p_{i, n}\right)\left(\mathrm{U}\left(x_{6, n}\right)\right. \\
& \left.-\mathrm{U}\left(x_{0, n}\right)\right) \cdot e_{i, n}^{p+} i=1, \ldots, 5, \\
\mathrm{U}\left(y_{i, n}\right)-\mathrm{U}\left(y_{0, n}\right)= & w^{-}\left(p_{i, n}\right)\left(\mathrm{U}\left(y_{6, n}\right)\right. \\
& \left.-\mathrm{U}\left(y_{0, n}\right)\right) \cdot e_{i, n}^{p-} i=1, \ldots, 5, \\
w^{+}\left(\frac{1}{2}\right)\left(\mathrm{U}\left(b_{n}\right)-\mathrm{U}\left(x_{1, n}\right)\right)= & \left(1-w^{+}\left(\frac{1}{2}\right)\right) \mathrm{U}\left(x_{0, n}\right) \cdot e_{n}^{b}, \\
w^{-}\left(\frac{1}{2}\right)\left(\mathrm{U}\left(c_{n}\right)-\mathrm{U}\left(y_{1, n}\right)\right)= & \left(1-w^{-}\left(\frac{1}{2}\right)\right) \mathrm{U}\left(y_{0, n}\right) \cdot e_{n}^{c}, \\
w^{+}\left(\frac{1}{2}\right)\left(\mathrm{U}\left(d_{n}\right)-\mathrm{U}\left(x_{0, n}\right)\right)= & w^{-}\left(\frac{1}{2}\right)\left(\mathrm{U}\left(y_{0, n}\right)-\mathrm{U}\left(y_{1, n}\right)\right) \cdot e_{n}^{d},
\end{aligned}
$$

where we allow for a multiplicative stochastic error $\left(e_{i, n}^{\bullet}\right)$, including individualspecific effects $\eta_{n}^{\bullet}$ that capture differences in probability weighting between individuals $n$. In the superscripts, $o$ and $p$ denote outcomes and probabilities, respectively, and the + and - signs denote the gain and the loss domain. The letters $b, c$, and $d$, refer to the corresponding loss aversion questions (see Table 2).

The errors are assumed to be independently log-normally distributed with different variances, i.e., $e_{i, n}^{\bullet} \sim \operatorname{LN}\left(0, \sigma_{i}^{\bullet 2}\right)$. This is a Fechner model on the log of the value scale, similar to the model employed by Donkers et al. (2001).

The consequences of specifying different error structures in models of decision making under risk has attracted considerable attention since the seminal article by Hey and Orme (1994). There is, however, currently no consensus in the literature on what error structure to use (Hey 1995; Loomes and Sugden 1995, 1998; Carbone and Hey 2000; Hey 2005; Blavatskyy 2007). We chose a multiplicative specification over an additive one (e.g. Blavatskyy 2006), because it naturally satisfies monotonicity. An additive specification would require a truncated error distribution to 
satisfy monotonicity (Blavatskyy 2007), which is numerically much more involved. Also, we chose the common Fechner structure over a random preference specification or a "trembling hand" specification, two other popular stochastic models (Wilcox 2008). In the first stochastic framework, it would be hard to eliminate individual effects, whereas it is unclear how to implement the second in a continuous outcome context.

In order to eliminate the probability weighting terms and potential individual specific effects, subsequent outcome equations can be divided by one another. In order to make the current study consistent with Booij and van de Kuilen (2007), loss aversion is estimated using all the questions around the zero outcome. Taking logarithms then gives,

$$
\begin{aligned}
\varepsilon_{i, n}^{o+} & \equiv \ln \left(\frac{e_{i+1, n}^{o+}}{e_{i, n}^{o+}}\right)=\ln \left(\frac{\left.\mathrm{U}\left(x_{i+1, n}\right)-\mathrm{U}\left(x_{i, n}\right)\right)}{\mathrm{U}\left(x_{i, n}\right)-\mathrm{U}\left(x_{i-1, n}\right)}\right) \quad i=1, \ldots, 5 \\
\varepsilon_{i, n}^{o-} & \equiv \ln \left(\frac{e_{i+1, n}^{o-}}{e_{i, n}^{o-}}\right)=\ln \left(\frac{\mathrm{U}\left(y_{i+1, n}\right)-\mathrm{U}\left(y_{i, n}\right)}{\mathrm{U}\left(y_{i, n}\right)-\mathrm{U}\left(y_{i-1, n}\right)}\right) \quad i=1, \ldots, 5 \\
\varepsilon_{i, n}^{p+} & \equiv \ln \left(e_{i, n}^{p+}\right)=\ln \left(w^{+}\left(p_{i}\right) \frac{\mathrm{U}\left(x_{6, n}\right)-\mathrm{U}\left(x_{0, n}\right)}{\mathrm{U}\left(x_{i, n}\right)-\mathrm{U}\left(x_{0, n}\right)}\right) \quad i=1, \ldots, 5 \\
\varepsilon_{i, n}^{p-} & \equiv \ln \left(e_{i, n}^{p-}\right)=\ln \left(w^{-}\left(q_{i}\right) \frac{\mathrm{U}\left(y_{6, n}\right)-\mathrm{U}\left(y_{0, n}\right)}{\mathrm{U}\left(y_{i, n}\right)-\mathrm{U}\left(y_{0, n}\right)}\right) \quad i=1, \ldots, 5 \\
\varepsilon_{n}^{L A} & \equiv \ln \left(e_{n}^{d} \cdot e_{n}^{c} / e_{n}^{b}\right) \\
& =\ln \left(\frac{\left(1-w^{+}\left(\frac{1}{2}\right)\right)}{\left(1-w^{-}\left(\frac{1}{2}\right)\right)} \frac{\left(\mathrm{U}\left(d_{n}\right)-\mathrm{U}\left(x_{0, n}\right)\right)}{\left(\mathrm{U}\left(b_{n}\right)-\mathrm{U}\left(x_{1, n}\right)\right)} \frac{\left(\mathrm{U}\left(c_{n}\right)-\mathrm{U}\left(y_{0, n}\right)-\mathrm{U}\left(y_{1, n}\right)\right)}{(\mathrm{U})} \frac{\mathrm{U}\left(x_{0, n}\right)}{\mathrm{U}\left(y_{0, n}\right)}\right)
\end{aligned}
$$

where $L A$, denotes loss aversion. Under the assumptions of (5.1), (5.2), (5.3), (5.4), (5.5), (5.6) and (5.7), the transformed error terms, collected in $\varepsilon_{n}=\left(\varepsilon_{n}^{\prime o+}, \varepsilon_{n}^{\prime p+}, \varepsilon_{n}^{\prime o-}\right.$, $\left.\varepsilon_{n}^{\prime p-}, \varepsilon_{n}^{L A}\right)^{\prime}=\left(\varepsilon_{1, n}^{o+}, \ldots, \varepsilon_{5, n}^{o+}, \varepsilon_{1, n}^{o-}, \ldots, \varepsilon_{5, n}^{o-}, \varepsilon_{1, n}^{p+}, \ldots, \varepsilon_{5, n}^{p+}, \varepsilon_{1, n}^{p-}, \ldots, \varepsilon_{5, n}^{p-}, \varepsilon_{n}^{L A}\right)^{\prime}$, are normally distributed with zero mean and covariance matrix $\Sigma$. This matrix has offdiagonal elements equal to zero, except for the outcome Eqs.5.1 and 5.2. The first differencing applied to these equations generates a correlation between the subsequent error terms. For example, assuming constant error variance, the covariance matrix for positive outcomes is a tridiagonal matrix equal to

$$
\Sigma^{o+}=\operatorname{cov}\left[\varepsilon_{1, n}^{o+}, \ldots, \varepsilon_{5, n}^{o+}\right]=2 \sigma^{2}\left(\begin{array}{ccccc}
1 & -\frac{1}{2} & 0 & \cdots & 0 \\
-\frac{1}{2} & 1 & \ddots & \ddots & \vdots \\
0 & \ddots & \ddots & \ddots & 0 \\
\vdots & \ddots & \ddots & 1 & -\frac{1}{2} \\
0 & \cdots & 0 & -\frac{1}{2} & 1
\end{array}\right) .
$$


In this example, the correlation between each subsequent error is $-\frac{1}{2} \cdot{ }^{6}$ In general, the first off-diagonal elements will vary. Hence, we will assume the covariance matrices of the outcome domains $\left(\Sigma^{o+}, \Sigma^{o-}\right)$ to be fully flexible in the empirical analysis. Because the questions of the second part are not chained, we simply assume the matrixes $\Sigma^{p+}, \Sigma^{p-}$ to have equal (non-zero) diagonal and equal off-diagonal elements. By assuming non-zero off diagonal elements, within-subject correlation in the answers is accounted for. The mean of the diagonal and off-diagonal elements are given by $\bar{\sigma}$ and $\bar{\rho}$, respectively.

To estimate the model, we assume two popular parametric specifications. For utility, we take the common power specification, with a loss aversion factor $\lambda$, as specified by Kahneman and Tversky (1979). For the subjective weighting of cumulative probabilities, we take the frequently used linear-in-log-odds specification as first employed by Goldstein and Einhorn (1987). These parametric families have been shown to have a good fit to experimental data (Gonzalez and Wu 1999; Abdellaoui et al. 2008). ${ }^{7}$ The probability weighting functions of both domains are allowed to differ as is assumed in the modern version of prospect theory. We have

$$
\begin{aligned}
\mathrm{U}(x ; \alpha, \beta, \lambda) & = \begin{cases}x^{\alpha} & x \geq 0 \\
-\lambda(-x)^{\beta} & x<0\end{cases} \\
w^{+}\left(p ; \delta^{+}, \gamma^{+}\right) & =\frac{\delta^{+} p^{\gamma^{+}}}{\delta^{+} p^{\gamma^{+}}+(1-p)^{\gamma^{+}}} \\
w^{-}\left(p ; \delta^{-}, \gamma^{-}\right) & =\frac{\delta^{-} p^{\gamma^{-}}}{\delta^{-} p^{\gamma^{-}}+(1-p)^{\gamma^{-}}} .
\end{aligned}
$$

This gives the log-likelihood function:

$$
\ell\left(\alpha, \beta, \lambda, \delta^{+}, \gamma^{+}, \delta^{-}, \gamma^{-}\right)=\sum_{n=1}^{N}-\frac{1}{2}\left\{\ln 2 \pi+2 \ln |\Sigma|+\varepsilon_{n}^{\prime} \Sigma^{-1} \varepsilon_{n}\right\} .
$$

To estimate the model, we split up the likelihood and use a three-stage procedure (limited-information maximum likelihood, LIML) to estimate utilities, and subsequently the probability weighting function and loss aversion. This has two advantages. First of all, it will ensure that the estimated utility curve will not suffer from a functional-form misspecification bias due to misspecification of the probability weighting function. This is precisely what Wakker and Deneffe (1996) trade-off method is designed for. Using full-information maximum likelihood would eliminate this advantage by re-introducing an interaction between the estimation of probability weighting

\footnotetext{
6 To see this, consider the covariance of two subsequent errors in the gain domain: $\operatorname{cov}\left[\varepsilon_{1, n}^{o+}, \varepsilon_{2, n}^{o+}\right]$ $=\operatorname{cov}\left[\ln e_{1, n}^{o+}-\ln e_{0, n}^{o+}, \ln e_{2, n}^{o+}-\ln e_{1, n}^{o+}\right]=\operatorname{cov}\left[\ln e_{1, n}^{o+}, \ln e_{2, n}^{o+}\right]-\operatorname{cov}\left[\ln e_{1, n}^{o+}, \ln e_{1, n}^{o+}\right]-\operatorname{cov}\left[\ln e_{0, n}^{o+}\right.$, $\left.\ln e_{2, n}^{o+}\right]+\operatorname{cov}\left[\ln e_{0, n}^{o+}, \ln e_{1, n}^{o+}\right]=0-\sigma^{2}-0+0=-\sigma^{2}$. The correlation then becomes: $\operatorname{corr}\left[\varepsilon_{1, n}^{o+}, \varepsilon_{2, n}^{o+}\right]=$ $\operatorname{cov}\left[\varepsilon_{1, n}^{o+}, \varepsilon_{2, n}^{o+}\right] / \sqrt{\left(\operatorname{var}\left[\varepsilon_{1, n}^{o+}\right] \cdot \operatorname{var}\left[\varepsilon_{2, n}^{o+}\right]\right)}=-\sigma^{2} / \sqrt{\left(2 \sigma^{2} \cdot 2 \sigma^{2}\right)}=-\frac{1}{2}$.

7 In the context of discrete choice, Stott (2006) shows that the more parsimonious one-parameter specifications often provide a sufficient fit in terms of the Akaike information criterion.
} 
Table 4 Estimation strategy

\begin{tabular}{llll}
\hline & 1st stage (Outcomes) & 2nd stage (Probabilities) & 3rd stage (Loss Av.) \\
\hline Gains & Obtain $\hat{\alpha}$ & Obtain $\left(\hat{\delta}^{+}, \hat{\gamma}^{+}\right)$ & Obtain $\hat{\lambda}$ \\
Losses & Obtain $\hat{\beta}$ & Obtain $\left(\hat{\delta}^{-}, \hat{\gamma}^{-}\right)$ & \\
$\operatorname{cov}$ & $\Sigma^{o+}, \Sigma^{o-}$ & $\Sigma^{p+}, \Sigma^{p-}$ & $\sigma^{L A}$ \\
\hline
\end{tabular}

and utility curvature. Also, the outcome matching questions (Part I) are generally believed to be easier to respond to and give higher quality data. Hence, we base the estimate of utility only on the questions from the first part. In the second stage, the probability weighting functions are estimated using the estimates of utility from the first stage. Loss aversion is estimated in the final stage, taking the estimated utility and probability weighting functions as given. Table 4 summarizes the estimation strategy.

By splitting up the estimation we cannot determine the correlations between the errors of the different question modules (i.e. utilities and probabilities, gains and losses). This is unfortunate since it would be interesting to know whether there is unobserved heterogeneity that affects the answers in both domains in a structural way, but it does bias the results. ${ }^{8}$ The standard errors in the second and third stages are corrected for the uncertainty in the first-stage estimates by using the adjustment specified by Murphy and Topel (1985). ${ }^{9}$

\section{Results}

The model as such assumes homogeneity in preferences. A certain degree of heterogeneity can be implemented, however, by parameterizing the preference parameters $\boldsymbol{\varphi}=\left(\alpha, \beta, \lambda, \delta^{+}, \gamma^{+}, \delta^{-}, \gamma^{-}\right)^{\prime}$ by a linear combination of regressors, i.e. $\boldsymbol{\varphi}=\mathbf{B}^{\prime} \mathbf{X}$. Hence, apart from estimating the average shape of utility and probability weighting, we can test whether there are significant differences in these preferences with respect to variables such as age, gender, education, and income. The first row of estimates in Table 5 gives the results of the model with only a constant, while the second gives the model with the set of demographic variables that appear to be associated with prospect theory's parameters.

\footnotetext{
8 Note that for the same reason we would not be able to estimate any correlation between random coefficients if they were specified. This is done in Tu (2005), who is unable to identify most correlations, but the ones he does indicate a negative correlation in risk aversion caused by the outcome and probability domain. However, Tu's model is not non-parametrically identified, so it is unclear whether this correlation is genuine or stems from non-linearity.

9 The correction specified by Murphy and Topel (1985) amounts to calculating $\hat{V}_{2}^{M T}=\hat{V}_{2}+\hat{V}_{2}$ $\left[\hat{C} \hat{V}_{1} \hat{C}^{\prime}-\hat{R} \hat{V}_{1} \hat{C}^{\prime}-\hat{R} \hat{V}_{1} \hat{R}^{\prime}\right] \hat{V}_{2}$ where $\hat{V}_{1}$ and $\hat{V}_{2}$ are the respective first- and second-stage covariance estimates, and $\hat{\mathrm{C}}=\sum_{i=1}^{n}\left(\frac{\partial \ln \left(f_{i 2}\right)}{\partial \hat{\beta}_{2}}\right)\left(\frac{\partial \ln \left(f_{i 2}\right)}{\partial \hat{\beta}_{1}^{\prime}}\right)$ and $\hat{\mathrm{R}}=\sum_{i=1}^{n}\left(\frac{\partial \ln \left(f_{i 2}\right)}{\partial \hat{\beta}_{2}}\right)\left(\frac{\partial \ln \left(f_{i 1}\right)}{\partial \hat{\beta}_{1}^{\prime}}\right)$.
} 
Table 5 Maximum likelihood estimates

\begin{tabular}{|c|c|c|c|c|c|c|c|}
\hline & \multicolumn{7}{|c|}{ Preference parameter } \\
\hline & \multicolumn{3}{|l|}{ Gains } & \multicolumn{3}{|l|}{ Losses } & \multirow{2}{*}{$\begin{array}{l}\text { Loss. av. } \\
\lambda\end{array}$} \\
\hline & $\alpha$ & $\delta^{+}$ & $\gamma^{+}$ & $\beta$ & $\delta^{-}$ & $\gamma^{-}$ & \\
\hline Constant only & $\begin{array}{l}0.859 * * * \\
(0.018)\end{array}$ & $\begin{array}{l}0.772 * * * \\
(0.051)\end{array}$ & $\begin{array}{l}0.618 * * * \\
(0.038)\end{array}$ & $\begin{array}{l}0.826 * * * \\
(0.018)\end{array}$ & $\begin{array}{l}1.022 * * * \\
(0.083)\end{array}$ & $\begin{array}{l}0.592 * * * \\
(0.061)\end{array}$ & $\begin{array}{l}1.576^{* * * *} \\
(0.098)\end{array}$ \\
\hline Low amounts & $\begin{array}{l}-0.071^{* *} \\
(0.032)\end{array}$ & & & & & & $\begin{array}{l}0.009 \\
(0.147)\end{array}$ \\
\hline Female & & $\begin{array}{l}-0.103 * \\
(0.065)\end{array}$ & $\begin{array}{l}-0.074 \\
(0.062)\end{array}$ & & & & $\begin{array}{l}0.251 * \\
(0.157)\end{array}$ \\
\hline Age & $\begin{array}{l}0.003 * * * \\
(0.001)\end{array}$ & $\begin{array}{l}-0.004 \\
(0.004)\end{array}$ & $\begin{array}{l}-0.006 * * * \\
(0.002)\end{array}$ & & & & $\begin{array}{l}0.003 \\
(0.005)\end{array}$ \\
\hline High edu. & & & & & & & $\begin{array}{l}-0.318^{* * *} \\
(0.117)\end{array}$ \\
\hline $\ln ($ Income +1$)$ & & & & & & & $\begin{array}{l}-0.059^{*} \\
(0.044)\end{array}$ \\
\hline Constant & $\begin{array}{l}0.776 * * * \\
(0.053)\end{array}$ & $\begin{array}{l}0.999 * * * \\
(0.195)\end{array}$ & $\begin{array}{l}0.954 * * * \\
(0.099)\end{array}$ & $\begin{array}{l}0.826 * * * \\
(0.018)\end{array}$ & $\begin{array}{l}1.022 * * * \\
(0.083)\end{array}$ & $\begin{array}{l}0.592 * * * \\
(0.061)\end{array}$ & $\begin{array}{l}1.766^{* * * *} \\
(0.411)\end{array}$ \\
\hline $\bar{\sigma}^{2}$ & $0.188 * * *$ & $0.267 * * *$ & & $0.219 * * *$ & $0.302 * *$ & & $0.574 * * *$ \\
\hline $\bar{\rho}$ & $-0.354^{* * *}$ & $0.133 * * *$ & & $-0.363^{* * *}$ & 0.062 & & \\
\hline$\ell$ & -13870.9 & -16080.7 & & -14431.0 & -16896.4 & & -2195.1 \\
\hline$N$ & 814 & 366 & & 690 & 272 & & 438 \\
\hline
\end{tabular}

Note: Murphy-Topel standard errors in parenthesis. Significance levels (one-sided tests) */**/***: 10/5/1\%

\subsection{Utility curvature}

The estimated power for gains $(\hat{\alpha}=0.859)$ and for losses $(\hat{\beta}=0.826)$ are displayed in the first row of Table 5. Both parameters are significantly below one $(z=8.04$, $p$-value $=0.000$ and $z=9.87, p$-value $=0.000)$, and they are not significantly different from one another $(z=1.39, p$-value $=0.166)$. Our estimates are closer to linearity as compared to the parametric studies of Harrison and Rutström (2009) and Donkers et al. (2001), who found $(\hat{\alpha}, \hat{\beta})=(.71, .72)$ and $(.61, .61)$ respectively, which suggests that their parametric specifications may be inappropriate for separating utility from probability weighting. The estimates confirm diminishing sensitivity, both with respect to losses and to gains (Tversky and Kahneman 1992; Abdellaoui 2000; Abdellaoui et al. 2007b), and we cannot reject equal curvature in both domains in favor of the more recent hypothesis of partial reflection (Wakker et al. 2007).

These results are qualitatively similar to those obtained by Booij and van de Kuilen (2007). Their estimates, based on fitting a power function to individual level data, are somewhat closer to linearity $(\hat{\alpha}=0.94$ and $\hat{\beta}=0.92$ are found), but still significantly below one, and not significantly different from each other. This suggests that assuming homogeneity in utility curvature may lead to a small downward bias in the 
(A)

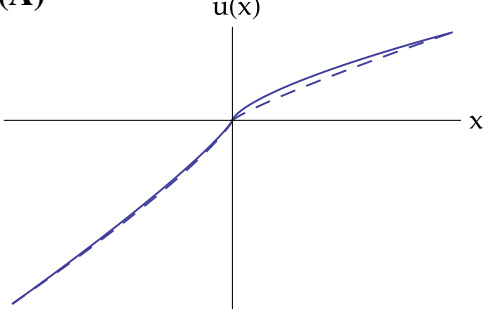

(B)

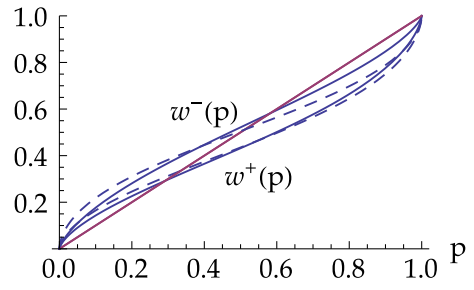

Fig. 3 Estimated utility and probability weighting functions. Note: The parameters of the solid lines are based on the averages of the estimates in Table 1. The dashed lines depict the estimated functions in this study. The loss-aversion parameter is assumed to be equal the average estimate of $\lambda=2.09$ form Table 1

estimate of the average,${ }^{10}$ while also providing evidence that any potential bias in the non-parametric analysis due to error propagation is unlikely to be of high magnitude. If we compare the coefficients to the average estimates of the literature reported in Table $1(\overline{\hat{\alpha}}=0.69$ and $\overline{\hat{\beta}}=0.86$ respectively), we find that the estimated power coefficient for gains is significantly higher $(z=9.61, p$-value $=0.000)$, while that of losses is significantly different at the $10 \%$ level only $(z=1.94, p$-value $=0.053)$. It should be noted that most recent estimates of utility curvature are much closer to linearity (Abdellaoui 2000; Etchart-Vincent 2004; Abdellaoui et al. 2005; Fehr-Duda et al. 2006; Abdellaoui et al. 2007b; Andersen et al. 2006; Abdellaoui et al. 2008) than what is suggested by the average estimate calculated from Table 1. Hence, our estimates fall within the range of contemporaneous estimates that find the power of the value function to be between .8 and 1. Figure 3 plots the estimated utility function (dashed line) and the average found in the literature (solid line). Indeed, the estimated utility curve for losses is very close to the literature average, while that of gains is a little more linear.

Table 5 also shows a significant treatment effect for gains. The low amounts treatment for gains (Low Amounts) are associated with a power coefficient that is .071 lower than for outcomes that are scaled up by a factor 10, suggesting that utility is more pronounced for low outcomes. This is not often found in the literature, though Cohn et al. (1975) and Blake (1996) report similar results. The effect is driven by the fact that, for gains, the last two mean elements of the standard sequence for low amounts are a bit higher than those in the high-amount treatment divided by 10 (see Table 3). It should be noted, however, that no significant difference was found in the non-parametric estimates. Because both approaches diverge, we will not draw strong conclusions with respect to this result.

\footnotetext{
${ }^{10}$ Effectively the non-parametric estimates of Booij and van de Kuilen (2007) allow for full heterogeneity in preferences, while the pooled estimation conducted in this article, does not. It is a priori not evident which method of analysis would yield the highest estimates, but it is clear that, because the model is non-linear, taking the average of estimates will yield a different result from that obtained by estimating the average directly.
} 


\subsection{Loss aversion}

Table 5 shows that we find a loss-aversion coefficient of $\hat{\lambda}=1.58$, which is lower than the parametric estimate of $\hat{\lambda}=2.25$ obtained by Tversky and Kahneman (1992), and the non-parametric estimate of $\hat{\lambda}=2.54$ that was found by Abdellaoui et al. (2007b), based on Köbberling and Wakker's (2005) definition (they find values below 2 for the other, global, definitions). Also, the obtained loss aversion parameter is lower than the average (non-parametric) estimate of $\hat{\lambda}=1.87$ obtained by Booij and van de Kuilen (2007), where estimation is conducted at the individual level. A similar effect is reported by Abdellaoui et al. (2008, p. 259) who find a pooled estimate of loss aversion that is lower than the average of the individual estimates. The obtained loss aversion is significantly larger than one $(z=5.88, p$-value $=0.000)$, and it is consistent with the recent estimates of Schmidt and Traub (2002); Gächter et al. (2007); Harrison and Rutström (2009) and Abdellaoui et al. (2008, pooled estimate) who find values of 1.43, $1.63,1.38$, and 1.60 , respectively. These and our results provide evidence that people weight a particular loss less than twice as heavy as a commensurable gain when making decisions. This is an interesting finding because Tversky and Kahneman (1992) original estimate of 2.25 seems to serve as the focal point estimate of loss aversion for many researchers, while many recent estimates find values below two.

Some studies have reported a decrease in the degree of loss aversion with the size of outcomes (Bleichrodt and Pinto 2002 (health); Abdellaoui et al. 2007b). Our point estimate of .004 for the Low Amount treatment (Table 5) does not provide additional support for this result.

\subsection{Probability weighting}

For both domains we estimated the elevation parameter $\delta$ and the curvature parameter $\gamma$ of the GE-87 probability weighting function specified in (5.15). ${ }^{11}$ The estimated elevation parameters point at pessimism with respect to gambling in both domains. For gains, we find $\hat{\delta}^{+}=0.772$, which is significantly lower than $1(z=4.46$, $p$-value $=0.000)$. This implies that a probability of a half is weighted by $\hat{w}^{+}(1 / 2)=$ 0.436 , which points to sizeable underweighting. This is close to Tversky and Kahneman (1992) original estimate of $\hat{w}^{+}(1 / 2)=0.421$, and it is not significantly different from the average estimated in the literature $(z=.23, p$-value $=0.818)$. For losses, the point estimate is $\hat{\delta}^{-}=1.022$ which is higher than one, also suggesting pessimism in the loss domain $\left(\hat{w}^{-}(1 / 2)=0.505>.5\right)$, but we cannot reject the hypothesis that $\delta=1(z=0.27, p$-value $=0.787)$. The elevation of the weighting function for losses is significantly higher than that of gains $(z=4.54, p$-value $=0.000)$ as was also found by Abdellaoui (2000); Abdellaoui et al. (2005), and Fehr-Duda et al. (2006), and we cannot reject the hypothesis that the elevation parameter is different from the literature average $($ Table 1$)$ of $\overline{\hat{\delta}}^{-}=1.09(z=.81, p$-value $=0.418)$. Contrary to

\footnotetext{
11 We find nearly identical results using the Prelec-2 specification (parameter values $\left(\hat{\delta}^{+}, \hat{\gamma}^{+}\right)=$ $(1.052,0.618)$ and $\left.\left(\hat{\delta}^{-}, \hat{\gamma}^{-}\right)=(0.870,0.653)\right)$. Hence, none of the conclusions drawn in this article change, if we use this specification in stead of GE-87.
} 
Etchart-Vincent (2004), who find more elevation for losses with higher stakes, we did not find any effect of the magnitude of the stakes on the degree of pessimism of the respondents.

The shape of the probability weighting function is primarily determined by $\gamma$, with $\gamma<1$ generating an inverse-S shape, and $\gamma>1$ a convex shape. Most studies that report a parametric estimate of the GE- 87 weighting function find evidence of an inverse-S shaped weighting function but, as mentioned in the introduction, some studies have found a convex-shaped weighting function. Interestingly, the point estimates for the degree of curvature in both domains are very similar, $\hat{\gamma}^{+}=0.618$ and $\hat{\gamma}^{-}=0.592$, and we cannot reject the hypothesis that both are equal $(z=.12$, $p$-value $=0.907$ ). Linearity, which requires $\gamma=1$, is clearly rejected in favor of the hypotheses that both parameters are below one $(z=10.02, p$-value $=0.000$ and $z=6.65, p$-value $=0.000)$, which means that we have found significant evidence for an inversely S-shaped weighting function in both domains. The degree of curvature we find is slightly higher than the average estimate in the literature. For gains the estimate is about .07 lower than the literature average $\left(\overline{\hat{\gamma}}^{+}=0.69\right)$, which is significant at the $10 \%$ level $(z=1.90, p$-value $=0.058)$. The estimate for losses is about .13 lower than the literature average $\left(\overline{\hat{\gamma}}^{-}=0.72\right)$, which is significant at the $5 \%$ level $(z=2.09$, $p$-value $=0.037)$. These results are illustrated graphically by the plot in Fig. 3, where the estimated weighting functions are slightly more pronounced than the literature averages for probabilities near 0 and 1 , while they are hardly distinguishable from the literature averages for intermediate probabilities.

\subsection{Demographics}

The dataset also contains background characteristics of the respondents such as their age, gender, education, and income. Table 5 gives the results of including regressors into the model, where most of the insignificant variables have been removed. The significance levels are reported for one-sided tests. Most of the variation in the behavioral parameters appears idiosyncratic, in particular for the domain of losses, where we do not find a significant effect for any variables. In the gain domain, we find a mild associations of age $(+0.003)$ with utility curvature, and a substantial gender effect on the elevation $(-0.103)$ of the probability weighting function. This last result is interesting because traditionally gender differences in risk-taking behavior have been ascribed to differences in utility curvature (e.g. Barsky et al. 1997). The analysis of Booij and van de Kuilen (2007) already showed that loss aversion may explain much of the gender differences in risk attitudes, which is also found here $(+0.251)$ and in other studies (e.g. Schmidt and Traub 2002). The current analysis further refines this by showing that part of this effect is also caused by differences in probability weighting. This is consistent with a recent study of Fehr-Duda et al. (2006), who report a significant gender difference in the elevation parameter of the GE-87 probability weighting function for gains but not for losses. These authors also find curvature to differ between the sexes, which we do not.

Older people seem to value money more linearly, with a 50-year age difference being associated with a power that is .15 higher. This effect works to reduce risk 
aversion, but it is countered by more non-linear weighting of probabilities $(-.30)$ that, in general, work to increase risk aversion. The total effect of these estimates depends on the prospects under study. For prospects that entail a small probability of a large gain, one may find risk aversion to decrease with age, while in those that do not, increasing risk aversion is more likely, which is what is usually found (Pålsson 1996; Donkers and van Soest 1999; Halek and Eisenhauer 2001; Hartog et al. 2002).

Education, defined as having a higher vocational or academic education, does not affect utility curvature, nor is it associated with a more linear weighting of probabilities. This latter effect is surprising if we view expected utility as the rational model of choice under risk. From that perspective, one may expect higher educated individuals to weight probabilities more linearly, which is not what we find. Education is associated with a lower degree of loss aversion $(-.318)$, which suggest that the reduction in risk aversion with years of schooling that is often observed (Donkers et al. 2001; Hartog et al. 2002; Dohmen et al. 2006) stems mainly from lower sensitivity to losses (e.g. Gächter et al. 2007).

Finally, the included (log) income variable showed a mild negative association with loss aversion, which is consistent with Gächter et al. (2007). Hence, we conjecture that mainly the loss aversion component of risk attitudes is driving the decrease in (absolute) risk aversion with income that is often found (Donkers et al. 2001; Hartog et al. 2002).

\subsection{Stochastics}

Table 3 shows considerable variability in the answers to the questions, which is picked up by the estimated error variances. The estimated variance-correlation matrices for the outcome equations are given in Table 6, where the diagonal elements correspond to the estimated variances, and the off-diagonal elements correspond to the estimated correlations between the error terms. The average variance $\bar{\sigma}^{2}$ is 0.188 for gains and 0.219 for losses. This means that the probability that the subsequent utility difference is twice as high (low) as the previous one is about 5\% (5\%). This may seem not very much, but it implies that in a standard sequence of six elements, there is about a $40 \%$ probability that there will be two subsequent utility increments that differ by a factor two. Although part of this variability is driven by between subjects heterogeneity, this result suggests that the assumption of a standard sequence without error is questionable.

Both estimated matrices have a tridiagonal structure, with the one off-diagonal correlation coefficients on average being equal to $\bar{\rho} \approx-0.35$ and the other correlations equal to zero. The negative correlations are a little weaker than the predicted correlation of $-\frac{1}{2}$ that follows under the assumption of equal variance, which means that not all underlying variances, $\sigma_{i}$, are equal. There does not appear to be much difference in the average variability of the answers for losses and for gains. The variance of the probability weighting questions is a little higher, 0.267 and 0.302 for gains and losses, respectively, which confirms that these questions are indeed more demanding for respondents. For gains, there appears to be some positive correlation between the individual answers $(\bar{\rho}=0.133)$, but not for losses. 


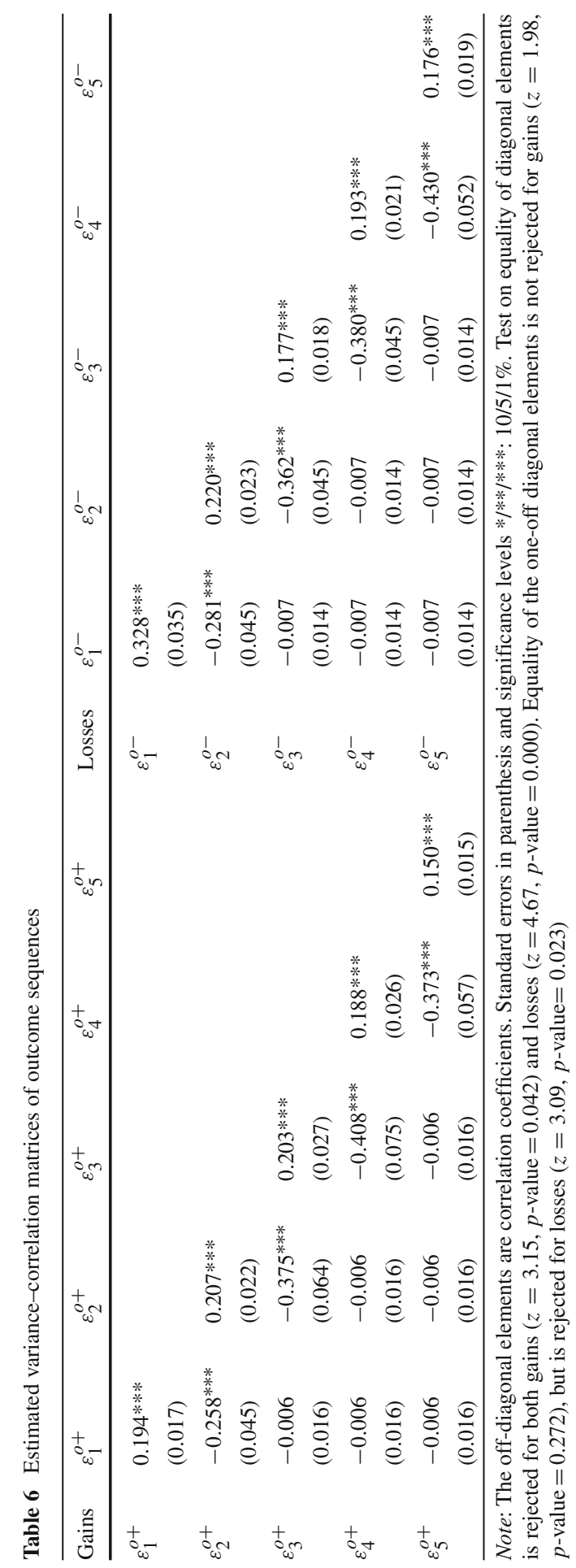




\section{Summary and conclusion}

This study presents the first, representative, large-scale parametric estimation of prospect theory's functionals, the utility function of money gains and losses, and the subjective probability weighting functions. Contrary to previous large scale parametric studies, the richness of the questionnaire allows for estimation of these curves without making too restrictive parametric assumptions, while allowing for response error in the individual answers. The results qualitatively confirm the non-parametric results of Booij and van de Kuilen (2007) and suggest that utility is mildly concave for gains and mildly convex for losses, implying diminishing sensitivity and suggesting that classical utility measurements that neglect probability weighting are overly concave.

A direct comparison with the non-parametric measures suggests that assuming homogeneity leads to a small downward bias, while providing evidence that a potential bias in a non-parametric analysis due to error propagation is unlikely to be large. Also our estimates are closer to linearity as compared to those of parametric studies that impose more stringent parametric assumptions (e.g. Donkers et al. 2001; Harrison and Rutström 2009), suggesting the utilities obtained in these studies may suffer from a contamination bias. Further, we find evidence that probabilities are weighted nonlinearly, with an inverse-S shape, and that both functions display pessimism (low elevation for gains, high elevation for losses). Hence, these results externally validate probability weighting that was found in a laboratory context (Wu and Gonzalez 1996; Abdellaoui 2000). The obtained degree of loss aversion, as operationalized by Tversky and Kahneman (1992), is 1.6. This is somewhat lower than their estimate of 2.25, but consistent with contemporaneous evidence (Schmidt and Traub 2002; Gächter et al. 2007; Abdellaoui et al. 2008). Furthermore, we found that neither the degree of utility curvature, nor the degree of loss aversion, is altered by scaling up monetary outcomes. The same holds for the probability weighting functions, which do not appear to be affected by the magnitude of the stakes, contrary to what Etchart-Vincent (2004) finds for the loss domain.

By including background characteristics, our estimation procedure gives more background as to what causes risk aversion differences between groups in the population. This analysis suggests that the common finding that women are more risk averse than males (Byrnes and Miller 1999) stems from differences in probability weighting and loss aversion, and not from differences in utility curvature. Also, the reduction of risk aversion that is associated with a higher level of education (Donkers et al. 2001; Dohmen et al. 2006) does not derive from utility curvature but from differences in loss aversion. The robustness of these results should be confirmed by further research, but they are indicative of the different channels through which risk-taking behavior is associated with background variables.

Two disadvantages of the study are the lack of real incentives and the use of matching tasks instead of choice tasks. Hypothetical tasks have been found in some settings to prime more erratic, and sometimes different, behavior than similar tasks involving real stakes (Camerer and Hogarth 1999; Holt and Laury 2002). Moreover, matching tasks have been found to increase the number of inconsistent answers, suggesting that these tasks are more cognitively demanding (Luce 2000; Hertwig and Ortmann 2001). This is confirmed by our data, where for gains $37 \%$ of all individuals gave 
one or more inconsistent answer. These individuals were excluded from the analysis, leading to sample selection. To correct for this, the analyses were conducted by using the inverse of the probability of appearing in the sample as weight. Given that our results blend in well with the results from laboratory experiments, providing evidence for diminishing sensitivity both with respect to outcomes and probabilities and also producing plausible relationships with demographic variables, we are confident that the obtained measures give a good representation of the average curvature of prospect theory's functionals.

Acknowledgements We thank Peter P. Wakker, Gregory Jolivet, and Sebastien Roux for their respective helpful comments and suggestions, and CentERdata, in particular Vera Toepoel, for programming the experiment and providing the data.

Open Access This article is distributed under the terms of the Creative Commons Attribution Noncommercial License which permits any noncommercial use, distribution, and reproduction in any medium, provided the original author(s) and source are credited.

\section{Appendix}

\subsection{Sample selection probit-equation}

Table 7 Sample selection equations

\begin{tabular}{|c|c|c|c|c|c|c|}
\hline \multirow[t]{2}{*}{ Variable } & \multirow[t]{2}{*}{ Frac. } & \multicolumn{2}{|l|}{ Outcomes } & \multicolumn{2}{|c|}{ Probabilities } & \multirow[t]{2}{*}{ Loss aversion } \\
\hline & & Gains & Losses & Gains & Losses & \\
\hline Low amounts treatment & $50 \%$ & $\begin{array}{l}0.144 * * \\
(0.058)\end{array}$ & $\begin{array}{l}0.101 * \\
(0.059)\end{array}$ & $\begin{array}{l}0.0123 \\
(0.18)\end{array}$ & $\begin{array}{l}-0.092 \\
(1.23)\end{array}$ & $\begin{array}{l}0.088 \\
(0.065)\end{array}$ \\
\hline Female & $46 \%$ & $\begin{array}{l}-0.052 \\
(0.060)\end{array}$ & $\begin{array}{l}-0.079 \\
(0.061)\end{array}$ & $\begin{array}{l}-0.188^{* *} \\
(2.65)\end{array}$ & $\begin{array}{l}-0.219^{* *} \\
(2.82)\end{array}$ & $\begin{array}{l}-0.116^{*} \\
(0.067)\end{array}$ \\
\hline Lower secondary education & $26 \%$ & $\begin{array}{l}0.127 \\
(0.142)\end{array}$ & $\begin{array}{l}0.029 \\
(0.143)\end{array}$ & $\begin{array}{l}-0.264 \\
(1.53)\end{array}$ & $\begin{array}{l}-0.370^{*} \\
(1.99)\end{array}$ & $\begin{array}{l}0.218 \\
(0.177)\end{array}$ \\
\hline Higher secondary education & $14 \%$ & $\begin{array}{l}0.335 * * \\
(0.151)\end{array}$ & $\begin{array}{l}0.148 \\
(0.152)\end{array}$ & $\begin{array}{l}0.169 \\
(0.96)\end{array}$ & $\begin{array}{l}0.106 \\
(0.56)\end{array}$ & $\begin{array}{l}0.507 * * * \\
(0.182)\end{array}$ \\
\hline Intermediate voc. training & $19 \%$ & $\begin{array}{l}0.046 \\
(0.146)\end{array}$ & $\begin{array}{l}-0.148 \\
(0.148)\end{array}$ & $\begin{array}{l}-0.127 \\
(0.73)\end{array}$ & $\begin{array}{l}-0.291 \\
(1.55)\end{array}$ & $\begin{array}{l}0.147 \\
(0.180)\end{array}$ \\
\hline Higher vocational training & $25 \%$ & $\begin{array}{l}0.258 * \\
(0.143)\end{array}$ & $\begin{array}{l}0.039 \\
(0.144)\end{array}$ & $\begin{array}{l}0.205 \\
(1.23)\end{array}$ & $\begin{array}{l}0.0662 \\
(0.37)\end{array}$ & $\begin{array}{l}0.394 * * \\
(0.175)\end{array}$ \\
\hline Academic education & $11 \%$ & $\begin{array}{l}0.488 * * * \\
(0.158)\end{array}$ & $\begin{array}{l}0.305^{*} \\
(0.158)\end{array}$ & $\begin{array}{l}0.568 * * \\
(3.16)\end{array}$ & $\begin{array}{l}0.447 * \\
(2.36)\end{array}$ & $\begin{array}{l}0.681 * * * \\
(0.187)\end{array}$ \\
\hline Age $35-44$ & $18 \%$ & $\begin{array}{l}-0.157^{*} \\
(0.092)\end{array}$ & $\begin{array}{l}-0.202^{* *} \\
(0.093)\end{array}$ & $\begin{array}{l}-0.0621 \\
(0.61)\end{array}$ & $\begin{array}{l}0.0567 \\
(0.53)\end{array}$ & $\begin{array}{l}-0.284^{* * *} \\
(0.099)\end{array}$ \\
\hline Age $45-54$ & $22 \%$ & $\begin{array}{l}-0.234^{* * *} \\
(0.088)\end{array}$ & $\begin{array}{l}-0.281^{\text {*** }} \\
(0.089)\end{array}$ & $\begin{array}{l}-0.258 * \\
(2.56)\end{array}$ & $\begin{array}{l}-0.195 \\
(1.79)\end{array}$ & $\begin{array}{l}-0.325^{* * *} \\
(0.095)\end{array}$ \\
\hline Age $55-64$ & $18 \%$ & $-0.313^{* * *}$ & $-0.340^{* * *}$ & $-0.273^{*}$ & $-0.418^{* * *}$ & $-0.524^{* * *}$ \\
\hline
\end{tabular}


Table 7 continued

\begin{tabular}{|c|c|c|c|c|c|c|}
\hline \multirow[t]{2}{*}{ Variable } & \multirow[t]{2}{*}{ Frac. } & \multicolumn{2}{|l|}{ Outcomes } & \multicolumn{2}{|l|}{ Probabilities } & \multirow[t]{2}{*}{ Loss aversion } \\
\hline & & Gains & Losses & Gains & Losses & \\
\hline & & $(0.094)$ & $(0.096)$ & $(2.52)$ & $(3.36)$ & $(0.106)$ \\
\hline Age $65+$ & $19 \%$ & $\begin{array}{l}-0.462^{* * *} \\
(0.095)\end{array}$ & $\begin{array}{l}-0.428^{* * *} \\
(0.096)\end{array}$ & $\begin{array}{l}-0.638^{* * *} \\
(5.44)\end{array}$ & $\begin{array}{l}-0.592^{* * *} \\
(4.63)\end{array}$ & $\begin{array}{l}-0.632^{* * *} \\
(0.108)\end{array}$ \\
\hline$€ 1.150 \leq$ Inc. $<€ 1.800$ & $25 \%$ & $\begin{array}{l}0.196 * \\
(0.118)\end{array}$ & $\begin{array}{l}0.269 * * \\
(0.122)\end{array}$ & $\begin{array}{l}0.298 \\
(1.94)\end{array}$ & $\begin{array}{l}0.480 * \\
(2.52)\end{array}$ & $\begin{array}{l}0.319 * * \\
(0.146)\end{array}$ \\
\hline$€ 1.800 \leq$ Inc. $<€ 2.600$ & $31 \%$ & $\begin{array}{l}0.200 * \\
(0.115)\end{array}$ & $\begin{array}{l}0.253 * * \\
(0.119)\end{array}$ & $\begin{array}{l}0.325^{*} \\
(2.16)\end{array}$ & $\begin{array}{l}0.509 * * \\
(2.71)\end{array}$ & $\begin{array}{l}0.381 * * * \\
(0.143)\end{array}$ \\
\hline Income $\geq € 2.600$ & $35 \%$ & $\begin{array}{l}0.344 * * * \\
(0.115)\end{array}$ & $\begin{array}{l}0.411^{* * *} \\
(0.119)\end{array}$ & $\begin{array}{l}0.418^{* *} \\
(2.80)\end{array}$ & $\begin{array}{l}0.699 * * * \\
(3.79)\end{array}$ & $\begin{array}{l}0.526^{* * *} \\
(0.142)\end{array}$ \\
\hline Catholic & $30 \%$ & $\begin{array}{l}0.014 \\
(0.068)\end{array}$ & $\begin{array}{l}0.008 \\
(0.069)\end{array}$ & $\begin{array}{l}0.0128 \\
(0.16)\end{array}$ & $\begin{array}{l}0.000 \\
(0.01)\end{array}$ & $\begin{array}{l}-0.007 \\
(0.077)\end{array}$ \\
\hline Protestant & $20 \%$ & $\begin{array}{l}0.160 * * \\
(0.077)\end{array}$ & $\begin{array}{l}0.126 \\
(0.078)\end{array}$ & $\begin{array}{l}0.136 \\
(1.52)\end{array}$ & $\begin{array}{l}0.083 \\
(0.85)\end{array}$ & $\begin{array}{l}0.215^{* *} \\
(0.084)\end{array}$ \\
\hline Constant & & $\begin{array}{l}-0.503^{* * *} \\
(0.176)\end{array}$ & $\begin{array}{l}-0.510^{* * *} \\
(0.179)\end{array}$ & $\begin{array}{l}-1.024^{* * *} \\
(4.75)\end{array}$ & $\begin{array}{l}-1.280^{* * *} \\
(5.21)\end{array}$ & $\begin{array}{l}-1.199^{* * *} \\
(0.217)\end{array}$ \\
\hline $\mathrm{N}$ & & 1935 & 1935 & 1935 & 1935 & 1935 \\
\hline
\end{tabular}

Notes: Standard errors allow for clustering within households. $* * * / * * *$ : significant at the $10 / 5 / 1 \%$ level

\subsection{Experimental instructions}

[Instructions are translated from Dutch]

Welcome at this experiment on individual decision making. The experiment is about your risk attitude. Some people like to take risks while other people like to avoid risks. The goal of this experiment is to gain additional insight into the risk attitude of people living in the Netherlands. This is very important for both scientists and policymakers. If we get a better understanding of how people react to situations involving risk, policy can be adjusted to take this into account (for example, with information provision on insurance and pensions, and advice for saving and investment decisions). Your cooperation at this experiment is thus very important and is highly appreciated.

The questions that will be posed to you during this experiment will not be easy. We therefore ask you to read the following explanation attentively. In this experiment, there are no right or wrong answers. It is exclusively about your own preferences. In those we are interested.

Probabilities (expressed in percentages) play an important role in this experiment. Probabilities indicate the likelihood of certain events. For example, you probably have once heard Erwin Krol say that the probability that it will rain tomorrow is equal to 20 percent $(20 \%)$. He then means, that rain will fall on 20 out of 100 similar days. During this experiment, probabilities will be illustrated using a wheel, as depicted below.

Suppose that the wheel depicted in the picture above is a wheel consisting of 100 equal parts. Possibly, you have seen such a wheel before in television shows such as The Wheel of Fortune. Now imagine that 25 out of 100 


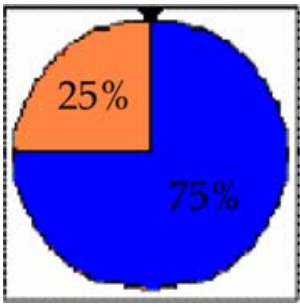

parts of the wheel are orange and that 75 out of 100 parts are blue. The probability that the black indicator on the top of the wheel points at an orange part after spinning the wheel is equal to $25 \%$ in that case. Similarly, the probability that the black indicator points at a blue part after spinning the wheel is equal to $75 \%$, because 75 out of 100 parts of the wheel are blue. The size of the area of a color on the wheel thus determines the probability that the black indicator will end on a part with that color.

Besides probabilities, lotteries play an important role in this experiment. Perhaps you have participated in a lottery such as the National Postal Code Lottery yourself before. In this experiment, lotteries yield monetary prizes with certain probabilities, similar to the National Postal Code Lottery. The prizes of the lotteries in this experiment can also be negative, however. If a lottery yields a negative prize, you should imagine yourself that you will have to pay the about amount of money. In the following explanation we will call a negative prize a loss and a positive prize a profit. During this experiment, lotteries will be presented like the example presented below:

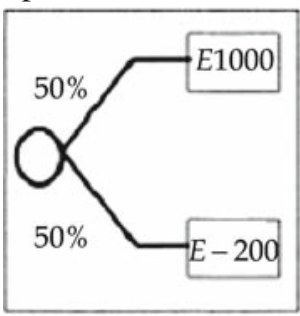

In this case, the lottery yields a profit of 1000 Euro with probability $50 \%$. However, with probability $50 \%$, this lottery yields a loss of 200 Euro. You should imagine that if you participated in this lottery, you would get 1000 Euro with probability $50 \%$, and with probability $50 \%$ you would have to pay 200 Euro.

During this experiment you will see two lotteries, named Lottery L (Left) and Lottery R (right), on the top of each page. Between these lotteries, you will see a wheel that serves as an aid to illustrate the probabilities used. You will see an example of the layout of the screen on the next page.

Lottery L

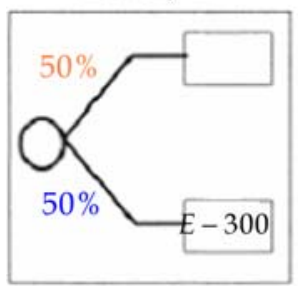

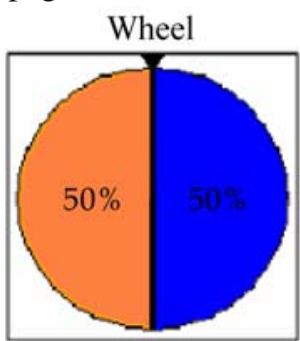

Lottery R

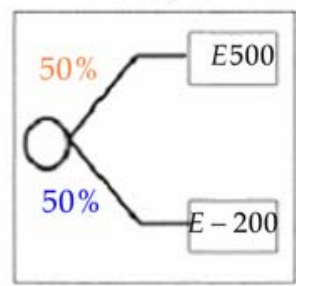


In this example, Lottery $\mathrm{R}$ yields a profit of 500 Euro with probability 50\%, and with a probability $50 \%$, it yields a loss of 200 Euro. You should imagine that, if we would spin the wheel once and the black indicator would point at the orange part of the wheel, then Lottery R would yield a profit of 500 Euro. However, if the black marker would point at the blue part of the wheel, the Lottery R would yield a loss of 200 Euro.

Similarly, Lottery L yields a loss of 300 Euro with a probability $50 \%$. However, as you can see, the upper prize of Lottery L is missing. During this experiment, we will repeatedly ask you for the upper prize of Lottery L (in Euro) that makes Lottery L and Lottery R equally good or bad for you. Thus, we will ask you for the upper prize of Lottery L for which you value both lotteries equally.

You could imagine that most people prefer Lottery L if the upper prize of Lottery L is very high, say 3000 Euro. However, if this prize is not so high, say 500 Euro, then most people would prefer Lottery R. Somewhere between these two prizes there is a "turnover point" for which you value both lotteries equally. For high prizes, you will prefer Lottery L and for low prizes you will prefer Lottery R. The turnover point is different for everybody and is determined by your own feeling. To help you a little bit in the choice process, we will report the range of prizes in which the answer of most people lies approximately at each question.

How this works precisely will become clear in the practice question that will start if you click on the CONTINUE button below. If something it not clear to you, you can read the explanation of this experiment again by pressing the BACK button below.

[Practice question]

The practice question is now over. The questions you will encounter during this experiment are very familiar to the practice question. If you click on the BEGIN button below, the experiment will start. If you want to go through the explanation of this experiment again, click on the EXPLANATION button. Good luck.

The first part of this experiment has now finished. In the second part of this experiment, each question will again be presented on a separate page, with two lotteries Lottery L (Left) and Lottery R (Right) presented at the top. In between the two lotteries, you will again be presented with a wheel to illustrate the probabilities. In this part of the experiment, however, Lottery L will always yield a fixed amount with certainty. Below the illustrated lotteries, there will again be text explaining the question. The next screen will show you an example of a question that you could get in the second part of this experiment.

Lottery L

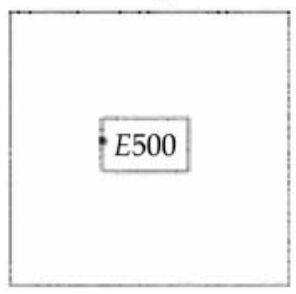

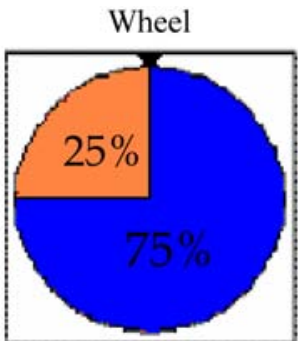

Lottery R

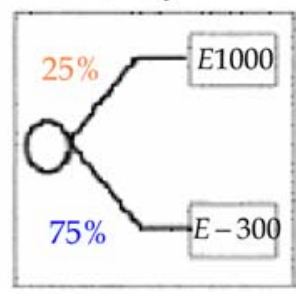

As you can see, in this example Lottery L always yields 500 Euros. Lottery R on the other hand, gives with probability $25 \%$ a profit of 1000 Euro, and with a probability of $75 \%$ a loss of 300 Euro. You should again imagine that, if we were to turn the wheel 
and the black pointer would be in the orange area, Lottery $\mathrm{R}$ would yield 1000 Euros. In case the black pointer would be in the blue area, Lottery R would yield a loss of 300 Euros.

Lottery L

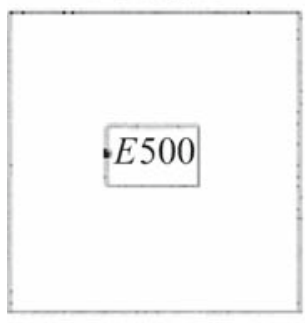

Wheel

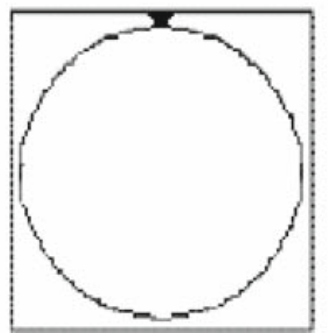

Lottery R

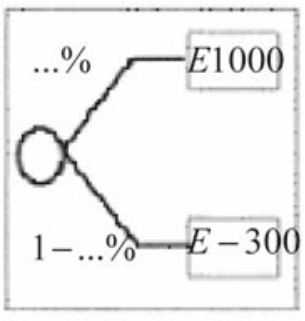

In the previous example you may have preferred Lottery L to Lottery R or the other way around. In the second part of this experiment, however, the probabilities of the prizes in lottery $\mathrm{L}$ will be missing, such as in the example given above.

In the second part of this experiment, we will ask you in each question to state the value of the missing probability (in whole percentages, from $0 \%$ to $100 \%$ ) for the upper prize of Lottery R that would make you value both equally.
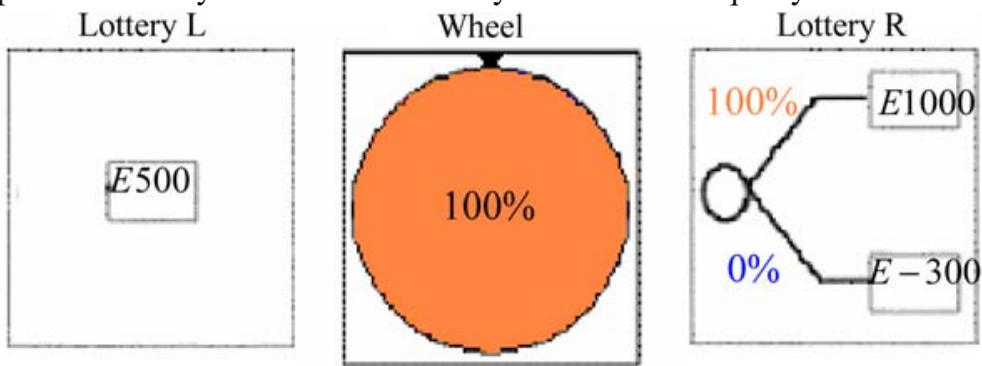

Imagine that the probability of the upper prize of lottery $\mathrm{R}$ is equal to $100 \%$. This would give the lotteries presented above. Lottery $\mathrm{L}$ will thus always give a profit of 500 Euro, while Lottery R will always give a 1000 Euros. Given that Lottery L will always yield less than Lottery R, most people will prefer Lottery R to Lottery R.

Lottery L

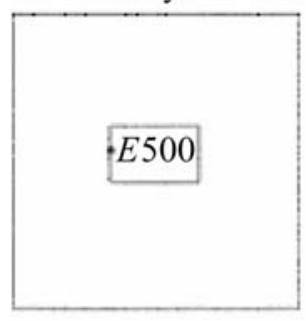

Wheel

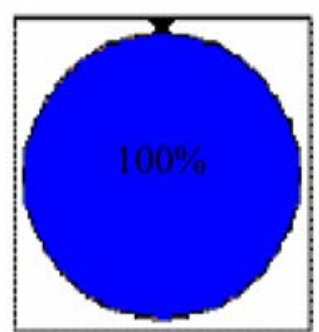

\section{Lottery R}

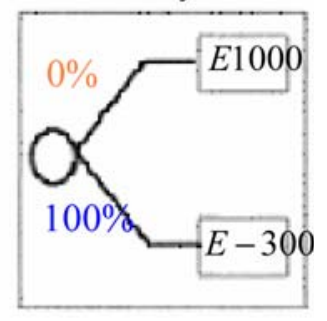

Imagine now, however, that the probability of the upper prize of lottery $\mathrm{R}$ is equal to $0 \%$. This would give the lotteries presented above. Lottery $\mathrm{L}$ will thus always give a profit of 500 Euro, while Lottery R will always give a loss of 300 Euros. Given that Lottery L will always yield more that Lottery $\mathrm{R}$, most people will now prefer Lottery L to Lottery R. 

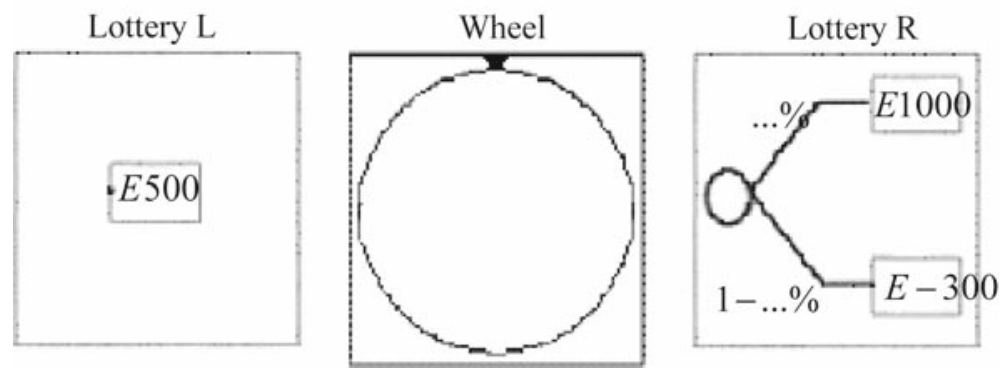

Hence, there is a value of the missing probability somewhere between $0 \%$ and $100 \%$ for which you would value both lotteries equally. In the questions that follow we will ask you for which value of the missing probability you value Lottery L and Lottery R equally. This missing probability can be different for everybody and is your own preference. How this works precisely will become clear in the practice question that will start if you click on the CONTINUE button below. If something it not clear to you, you can read the explanation of this experiment again by pressing the BACK button below.

[Practice question]

The practice question is now over. The questions you will encounter during this experiment are very familiar to the practice question. If you click on the BEGIN button below, the experiment will start. If you want to go through the explanation of the second part of this experiment again, click on the EXPLANATION button. Good luck.

\section{References}

Abdellaoui, M. (2000). Parameter-free elicitation of utilities and probability weighting functions. Management Science, 46, 1497-1512.

Abdellaoui, M., Barrios, C., \& Wakker, P. P. (2007a). Reconciling introspective utility with revealed preference: experimental arguments based on prospect theory. Journal of Econometrics, 138, 356-378.

Abdellaoui, M., Bleichrodt, H., \& L'Haridon, O. (2008). A tractable method to measure utility and loss aversion under prospect theory. Journal of Risk and Uncertainty, 36, 245-266.

Abdellaoui, M., Bleichrodt, H., \& Paraschiv, C. (2007b). Loss aversion under prospect theory: A parameter-free measurement. Management Science, 50(10), 1659-1674.

Abdellaoui, M., Vossmann, F., \& Weber, M. (2005). Choice-based elicitation and decomposition of decision weights for gains and losses under uncertainty. Management Science, 51, 1384-1399.

Allais, M. (1953). Le Comportement de l'Homme Rationnel devant le Risque: critique des Postulats et Axiomes de l'Ecole Américaine. Econometrica, 21, 503-546.

Andersen, S., Harrison, G. W., Lau, M. I., \& Rutström, E. (2008). Eliciting risk and time preferences. Econometrica, 76(3), 583-618.

Andersen, S., Harrison, G. W., \& Rutström, E. E. (2006). Dynamic choice behaviour: asset integration and natural reference points. Working paper, 06-07, Department of Economics, College of Business Administration, University of Central Florida. Available at http://www.bus.ucf.edu/wp/Working\%20Papers/ 2006/06-07\%20Harrison.pdf.

Barsky, R. B., Juster, F. T., Kimball, M. S., \& Shapiro, M. D. (1997). Preference parameters and behavioral heterogeneity: an experimental approach in the health and retirement study. Quarterly Journal of Economics, 112, 537-579.

Benartzy, S., \& Thaler, R. H. (1995). Myopic loss aversion and the equity premium puzzle. Quarterly Journal of Economics, 110, 73-92.

Blake, D. (1996). Efficiency, risk aversion and portfolio insurance: an analysis of financial asset portfolios held by investors in the United Kingdom. Economic Journal, 106, 1175-1192. 
Blavatskyy, P. (2006). Error propagation in the elicitation of utility and probability weighting functions. Theory and Decision, 60, 315-334.

Blavatskyy, P. R. (2007). Stochastic expected utility theory. Journal of Risk and Uncertainty, 34, 259-286.

Bleichrodt, H., \& Pinto, J. L. (2000). A parameter-free elicitation of the probability weighting function in medical decision analysis. Management Science, 46, 1485-1496.

Bleichrodt, H., \& Pinto, J. L. (2002). Loss aversion and scale compatibility in two-attribute trade-offs. Journal of Mathematical Psychology, 46, 315-337.

Booij, A. S., \& van de Kuilen, G. (2007). A parameter-free analysis of the utility of money for the general population under prospect theory. Working paper, Amsterdam School of Economics. Available at http:// booij.economists.nl/papers.php.

Byrnes, J. P., \& Miller, D. C. (1999). Gender differences in risk taking: a meta-analysis. Psychological Bulletin, 125(3), 367-383.

Camerer, C. F. (2000). Prospect theory in the wild: evidence from the field. In D. Kahneman \& A. Tversky (Eds.), Choices, values and frames (pp. 288-300). New York: Cambridge University Press.

Camerer, C. F., \& Ho, T. (1994). Nonlinear weighting of probabilities and violations of the betweenness axiom. Journal of Risk and Uncertainty, 8, 167-196.

Camerer, C. F., \& Hogarth, R. M. (1999). The effects of financial incentives in experiments: a review and capital-labor-production framework. Journal of Risk and Uncertainty, 19, 7-42.

Carbone, E., \& Hey, J. D. (2000). Which error story is best? Journal of Risk and Uncertainty, 20(2), 161-176.

Cohn, R. A., Lewellen, W. G., Lease, R. C., \& Schlarbaum, G. G. (1975). Individual investor risk aversion and investment portfolio composition. Journal of Finance, 30, 605-620.

Cox, J. C., \& Sadiraj, V. (2006). Small- and large-stakes risk aversion: implications of concavity calibration for decision theory. Games and Economic Behavior, 56(1), 45-60.

Cubitt, R. P., Starmer, C., \& Sugden, R. (2001). Discovered preferences and the experimental evidence of violations of expected utility theory. Journal of Economic Methodology, 8, 385-414.

Currim, I. S., \& Sarin, R. K. (1989). Prospect versus utility. Management Science, 35, 22-41.

Davidson, D., Suppes, P., \& Siegel, S. (1957). Decision making: an experimental approach. Stanford, CA: Stanford University Press.

Dohmen, T., Falk, A., Huffman, D., Sunde, U., Schupp, J., \& Wagner, G. G. (2006). Individual risk attitudes: new evidence from a large, representative, experimentally-validated survey. CEPR Discussion Papers 5517.

Donkers, A. C. D., Melenberg, B., \& van Soest, A. H. O. (2001). Estimating risk attitudes using lotteries: a large sample approach. Journal of Risk and Uncertainty, 22, 165-195.

Donkers, B., \& van Soest, A. (1999). Subjective measures of household preferences and financial decisions. Journal of Economic Psychology, 20, 613-642.

Etchart-Vincent, N. (2004). Is probability weighting sensitive to the magnitude of consequences? An experimental investigation on losses. Journal of Risk and Uncertainty, 28, 217-235.

Fehr-Duda, H., de Gennaro, M., \& Schubert, R. (2006). Gender, financial risk, and probability weights. Theory and Decision 60, 283-313.

Fennema, H., \& van Assen, M. A. L. M. (1998). Measuring the utility of losses by means of the tradeoff method. Journal of Risk and Uncertainty, 17, 277-295.

Gächter, S. E., Johnson, J., \& Herrmann, A. (2007). Individual-level loss aversion in riskless and risky choices. Working paper, CeDEx discussion paper 2007-02, The University of Nottingham. Available at http://www.nottingham.ac.uk/economics/cedex/papers/2007-02.pdf.

Goeree, J. K., Holt, C. A., \& Palfrey, T. R. (2002). Quantal response equilibrium and overbidding in private-value auctions. Journal of Economic Theory, 104, 247-272.

Goette, L., Huffman, D., \& Fehr, E. (2004). Loss aversion and labour supply. Journal of the European Economic Association, 2, 216-228.

Goldstein, W. M., \& Einhorn, H. J. (1987). Expression theory and the preference reversal phenomena. Psychological Review, 94, 236-254.

Gonzalez, R., \& Wu, G. (1999). On the form of the probability weighting function. Cognitive Psychology, $38,129-166$.

Guiso, L., \& Paiella, M. (2003). Risk aversion, wealth and background risk. Bank of Italy economic working paper no. 483.

Halek, M., \& Eisenhauer, J. G. (2001). Demography of risk aversion. Journal of Risk and Insurance, 68, $1-34$. 
Harrison, G. W., Lau, M. I., Rutström, E. E., \& Sullivan, M. B. (2005). Eliciting risk and time preferences using field experiments: some methodological issues. Field experiments in economics (Vol. 10). Greenwich, CT: JAI Press (Research in Experimental Economics).

Harrison, G. W., \& Rutström, E. E. (2008). Risk aversion in the laboratory. In J. C. Cox \& G. W. Harrison (Eds.), Risk aversion in experiments (Vol. 12, pp. 42-196). Bingley, UK: Emerald (Research in experimental economics).

Harrison, G. W., \& Rutström, E. E. (2009). Expected utility theory and prospect theory: One wedding and a decent funeral. Experimental Economics 12, forthcoming. Available at http://www.bus.ucf.edu/wp/ Working\%20Papers/2005/05-18\%20Harrison.pdf.

Hartog, J., Ferrer-i-Carbonell, A., \& Jonker, N. (2002). Linking measured risk aversion to individual characteristics. Kyklos, 55, 3-26.

Hertwig, R., \& Ortmann, A. (2001). Experimental practices in economics: a challenge for psychologists? Behavioral and Brain Sciences, 24, 383-403.

Hey, J. D. (1995). Experimental investigations of errors in decision making under risk. European Economic Review, 39(3-4), 633-640.

Hey, J. D. (2005). Why we should not be silent about noise. Experimental Economics, 8(4), 325-345.

Hey, J. D., \& Orme, C. (1994). Investigating generalizations of expected utility theory using experimental data. Econometrica, 62, 1291-1326.

Holt, C. A., \& Laury, S. K. (2002). Risk aversion and incentive effects. American Economic Review, 92, 1644-1655.

Jullien, B., \& Salanié, B. (2000). Estimating preferences under risk: the case of racetrack bettors. Journal of Political Economy, 108, 503-530.

Kahneman, D., \& Tversky, A. (1979). Prospect theory: an analysis of decision under risk. Econometrica, 47, 263-291.

Köbberling, V., \& Wakker, P. P. (2005). An index of loss aversion. Journal of Economic Theory, 122(1), 119-131.

Laury, S. K., \& Holt, C. A. (2000). Further reflections on prospect theory. Atlanta, GA: Department of Economics, Georgia State University.

Loomes, G., \& Sugden, R. (1995). Incorporating a stochastic element into decision theories. European Economic Review, 39(3/4), 641-648.

Loomes, G., \& Sugden, R. (1998). Testing different stochastic specifications of risky choice. Economica, 65(260), 581-598.

Luce, R. D. (2000). Utility of gains and losses: Measurement-theoretical and experimental approaches. London: Lawrence Erlbaum Publishers.

McGlothlin, W. H. (1956). Stability of choices among uncertain alternatives. American Journal of Psychology, 69, 604-615.

Murphy, K. M., \& Topel, R. H. (1985). Estimation and inference in two-step econometric models. Journal of Business and Economic Statistics, 3(4), 370-379.

Pålsson, A. (1996). Does the degree of relative risk aversion vary with household characteristics. Journal of Economic Psychology, 17, 771-787.

Prelec, D. (1998). The probability weighting function. Econometrica 66, 497-527.

Rabin, M. (2000). Risk aversion and expected-utility theory: a calibration theorem. Econometrica, 68, 1281-1292.

Rubinstein, A. (2006). Dilemmas of an economic theorist. Econometrica, 74, 865-883.

Schmidt, U., \& Traub, S. (2002). An experimental test of loss aversion. Journal of Risk and Uncertainty, $25,233-249$.

Starmer, C. (2000). Developments in non-expected utility theory: the hunt for a descriptive theory of choice under risk. Journal of Economic Literature, 38, 332-382.

Stott, H. (2006). Cumulative prospect theory's functional menagerie. Journal of Risk and Uncertainty, 32, $101-130$.

Tu, Q. (2005). Empirical analysis of time preferences and risk aversion. CentER PhD Thesis 142, Tilburg University.

Tversky, A., \& Fox, C. R. (1995). Weighing risk and uncertainty. Psychological Review 102, 269-283.

Tversky, A., \& Kahneman, D. (1992). Advances in prospect theory: Cumulative representation of uncertainty. Journal of Risk and Uncertainty 5, 297-323. 
van de Kuilen, G., \& Wakker, P. P. (2009). The midweight method to measure attitudes towards risk and ambiguity. Working paper, Econometric Institute, Erasmus University Rotterdam. http://people.few.eur. nl/wakker/pdf/wmidpoint.pdf

Von Gaudecker, H. M., van Soest, A., \& Wengström, E. (2008). Selection and mode effects in risk preference elicitation. IZA discussion paper 3321. Available at http://ftp.iza.org/dp3321.pdf.

Wakker, P. P. (1994). Separating marginal utility and probabilistic risk aversion. Theory and Decision, 36, $1-44$.

Wakker, P. P. (2005). Formalizing reference dependence and initial wealth in Rabin's calibration theorem. Working paper, Econometric Institute, Erasmus University Rotterdam. Available at http://people.few. eur.nl/wakker/pdf/calibcsocty05.pdf

Wakker, P. P. (2008). Explaining the characteristics of the power (CRRA) utility function. Health Economics, 17, 1329-1344.

Wakker, P. P., \& Deneffe, D. (1996). Eliciting von Neumann-Morgenstern utilities when probabilities are distorted or unknown. Management Science, 42, 1131-1150.

Wakker, P. P., Köbberling, V., \& Schwieren, C. (2007). Prospect-theory's diminishing sensitivity versus economic's intrinsic utility of money: How the introduction of the euro can be used to disentangle the two empirically. Theory and Decision, 63, 205-231.

Wakker, P. P., Thaler, R. H., \& Tversky, A. (1997). Probabilistic insurance. Journal of Risk and Uncertainty, 15, 7-28.

Wakker, P. P., \& Tversky, A. (1993). An axiomatization of cumulative prospect theory. Journal of Risk and Uncertainty, 7, 147-176.

Wilcox, N. T. (2008). Stochastic models for binary discrete choice under risk: a critical primer and econometric comparison. In J. C. Cox \& G. W. Harrison (Eds.), Risk aversion in experiments (Vol. 12, pp. 197-292) Greenwich, CT: JAI Press (Research in Experimental Economics).

Wu, G., \& Gonzalez, R. (1996). Curvature of the probability weighting function. Management Science, 42, $1676-1690$. 